\title{
How do judgmental overconfidence and overoptimism shape innovative activity?
}

Herz, Holger ; Schunk, Daniel ; Zehnder, Christian

\begin{abstract}
Recent field evidence suggests a positive link between overconfidence and innovative activities. In this paper we argue that the connection between overconfidence and innovation is more complex than the previous literature suggests. In particular, we show theoretically and experimentally that different forms of overconfidence may have opposing effects on innovative activity. While overoptimism is positively associated with innovation, judgmental overconfidence is negatively linked to innovation. Our results indicate that future research is well advised to take into account that the relationship between innovation and overconfidence may crucially depend on what type of overconfidence is most prevalent in a particular context.
\end{abstract}

DOI: https://doi.org/10.1016/j.geb.2013.11.001

Posted at the Zurich Open Repository and Archive, University of Zurich ZORA URL: https://doi.org/10.5167/uzh-100554

Journal Article

Accepted Version

Originally published at:

Herz, Holger; Schunk, Daniel; Zehnder, Christian (2014). How do judgmental overconfidence and overoptimism shape innovative activity? Games and Economic Behavior, 83:1-23.

DOI: https://doi.org/10.1016/j.geb.2013.11.001 


\title{
How Do Judgmental Overconfidence and Overoptimism Shape Innovative Activity?
}

\author{
Holger Herz, Daniel Schunk and Christian Zehnder*
}

November 7, 2013

\begin{abstract}
Recent field evidence suggests a positive link between overconfidence and innovative activities. In this paper we argue that the connection between overconfidence and innovation is more complex than the previous literature suggests. In particular, we show theoretically and experimentally that different forms of overconfidence may have opposing effects on innovative activity. While overoptimism is positively associated with innovation, judgmental overconfidence is negatively linked to innovation. Our results indicate that future research is well advised to take into account that the relationship between innovation and overconfidence may crucially depend on what type of overconfidence is most prevalent in a particular context.
\end{abstract}

Keywords: Innovation, Entrepreneurship, Overconfidence, Experiment. JEL Classification Codes: C92, D83, D23

*Holger Herz: University of Zurich, Blümlisalpstr. 10, CH-8006 Zürich, holger.herz@econ.uzh.ch. Daniel Schunk: Department of Economics, University of Mainz, Jakob Welder Weg 4, D-55099 Mainz, daniel.schunk@uni-mainz.de. Christian Zehnder: Faculty of Business and Economics, University of Lausanne, Quartier UNIL-Dorigny, Internef 612, CH-1015 Lausanne, christian.zehnder@unil.ch. We are grateful to Stefan Bechtold, Florian Ederer, Ernst Fehr, Michael Kosfeld, Gustavo Manso, Dana Sisak, Eric Zwick and seminar participants at Boston University, Harvard University, the University of Zurich and ETH Zurich as well as participants of the ESA International Meetings 2010 at the University of Copenhagen and the Meeting of the European Economics Association 2012 in Malaga for helpful suggestions and comments. 


\section{Introduction}

Recent field evidence indicates that there is a positive link between overconfidence of managerial decision makers and innovative activities. For example, Galasso and Simcoe (2011) and Hirshleifer et al. (2012) show that CEOs who are overoptimistic regarding the future performance of their company, are more likely to pursue innovation, obtain more patents and patent citations, and are more likely to take their firms in a new technological direction. In this paper we argue that the connection between overconfidence and innovation is more complex than the previous literature suggests. Existing work focuses almost exclusively on overoptimism, the tendency of individuals to overestimate their abilities or chances of success. However, while there is indeed ample evidence indicating that people often exhibit this bias (see, e.g., Svenson, 1981; Dunning et al., 1989; Alicke et al., 1995), many studies show that other forms of overconfidence are also prevalent. In particular, it is a well established fact that many people have a tendency to overestimate the precision of their information. This phenomenon is commonly referred to as judgmental overconfidence (see, e.g., Lichtenstein et al., 1982; Russo and Schoemaker, 1992). In this paper we show theoretically and experimentally that the effect of judgmental overconfidence on innovative activity goes in the opposite direction of the effect of overoptimism, i.e., judgmental overconfidence is negatively associated with innovation. Our results indicate that future research is well advised to take into account that the relationship between innovation and overconfidence may crucially depend on what type of overconfidence is most prevalent in a particular context.

To cleanly isolate the effects of judgmental overconfidence and overoptimism on innovative activities, we rely on the methods of experimental economics. We implement a modified version of a management task developed by Ederer and Manso (2013) in our laboratory. This task confronts our participants with one of the core features of the innovative process: the trade-off between exploration and exploitation (see, e.g., March, 1991, for an extensive discussion). ${ }^{1}$ Specifically, our subjects take on the role of a manager of an ice cream stand, whose aim is to find the product mix that maximizes the profit of the ice cream stand. The participants are provided with a default business strategy which delivers a known level of profit. Fine-tuning this strategy (exploitation) allows to increase profits to a certain extent. However, in order to increase profits substantially, the participants need to be willing to change the product mix radically (exploration). In addition to completing the innovation task, our subjects also participate in a number of experimental tests that allow us to elicit measures for judgmental overconfidence and overoptimism, as well as to gather proxies for

\footnotetext{
${ }^{1}$ Obviously, innovative activities also include other aspects such as creativity, initiative, and implementation. The focus of our study, however, is on the strategic part of innovation, i.e., on the decision when to stop the exploratory process of searching for novel ideas.
} 
intelligence and ambiguity aversion.

To substantiate the intuitive hypothesis that judgmental overconfidence and overoptimism have opposing associations with innovative activity, we formally analyze a stylized version of our laboratory environment. We consider a setup in which an agent has the choice between exploitation of the best business strategy currently available to him and exploration of a novel business strategy in each of a finite number of periods. We show that overoptimism (formalized as an upwardly biased belief about the average profitability of exploration) leads to excessive exploration, while judgmental overconfidence (formalized as an underestimation of the variance in exploratory profits) implies that there is too little exploration.

The experimental data confirm the theoretical prediction that judgmental overconfidence has a significantly negative predictive effect on innovative activity. Participants who exhibit higher degrees of judgmental overconfidence engage in shorter exploratory phases, stop exploring at lower profit levels, are less likely to systematically keep track of their exploratory outcomes, and explore a smaller number of new flavors. Moreover, the data also support the hypothesis that judgmental overconfidence is associated with suboptimal business strategies which lead to both lower overall profits as well as lower maximum per-period profits. Taken together, these results corroborate the fact that judgmental overconfidence has a decisive impact on innovative activity at the individual level.

With regard to overoptimism our theoretical analysis predicts an exploration enhancing effect, which ultimately leads to the implementation of a superior business strategy. However, while the implementation of a superior business strategy boosts maximum per-period profits, the additional costs necessary to obtain such a strategy exceed the additional benefits so that the effect on total profits is hypothesized to be negative. Our experimental data provides some support for a positive association between overoptimism and exploration and a negative association with profits, but these associations are weak and remain mostly insignificant. Note, however, that the prediction that overoptimism leads to the implementation of superior business strategies is well aligned with the field evidence mentioned above. Galasso and Simcoe (2011) and Hirshleifer et al. (2012) both find a robust positive association between CEO overconfidence, R\&D expenditures and citation-weighted patent counts, confirming that overconfidence leads to more and ultimately better innovations. ${ }^{2}$

One potential concern with our approach to study individual innovative activity is that the results may not be generalizable to settings outside the laboratory. Previous studies have not tested whether the experimental exploration-exploitation trade-off implied by the experimental management game is related to real-life innovative activity. To close this gap

\footnotetext{
${ }^{2}$ Since they do not observe the opportunity costs of R\&D, the net effect on firm profits cannot be properly addressed with these data.
} 
we test the external validity of our behavioral measure using a sample of middle-managers of a financial services company. The managers not only participated in our laboratory experiment, but we also surveyed their superiors in their company to collect external data on their individual innovative activity and performance at the workplace. We find a strong and significant correlation between performance in the experimental task and external measures of creativity, performance, gestalt motivation and taking charge behavior. These findings suggest that our laboratory setting is well suited to study the determinants and antecedents of innovative behavior at the individual level.

Our paper extends existing research in several ways. First, our study contributes to a small, but growing literature on the individual determinants of innovative activity. While the literature on the role of innovation at the industry and firm level has made immense progress in recent years (for recent reviews of this literature see, e.g., Hulten, 2010; Arora and Gambardella, 2010; Hall and Lerner, 2010; Fagerberg et al., 2010), our understanding of the individual determinants of innovative activity is still quite limited. ${ }^{3}$ However, there is an emerging literature suggesting that behavioral biases such as overconfidence may have an important impact on people's entrepreneurial and innovative behavior. The general view taken in this research is that individuals are overoptimistic with regard to the returns of potential innovations, for example by overestimating success probabilities of implementing an innovation, which in turn leads to excessive innovation, entrepreneurial activity and market entrance (see, for example, Camerer and Lovallo, 1999; Bernardo and Welch, 2001; Lowe and Ziedonis, 2006; Galasso and Simcoe, 2011; Hirshleifer et al., 2012). Our work not only confirms the relevance of this channel, but also clarifies that it is of great importance to distinguish between overoptimism and judgmental overconfidence. This point is crucial, because these two forms of overconfidence have not always been clearly distinguished in earlier work, although they represent two very different types of biases (see, e.g., Moore and Healy, 2008; Hilton et al., 2011; Heger and Papageorge, 2012, for a discussion).

Second, our study is related to previous work investigating the link between overconfidence and various forms of performance. For example, Benos (1998), Daniel et al. (1998), and Odean (1998) theoretically link judgmental overconfidence to poor trading performance in financial markets and Biais et al. (2005) provide experimental evidence in support of this relationship. Bolton et al. (2013) show that judgmental overconfidence can be a beneficial attribute of a leader because it can facilitate coordination. We add a new angle to this literature by differentiating the effects of overoptimism and judgmental overconfidence on

\footnotetext{
${ }^{3}$ There is an extensive literature on individual determinants in the entrepreneurship literature. However, this work focuses mainly on characteristics such as wealth, age, education, risk and other socio-demographic characteristics (see, e.g., Kihlstrom and Laffont, 1979; Evans and Leighton, 1989; Blanchflower and Oswald, 1998; Hurst and Lusardi, 2004).
} 
individuals' innovative activity.

Relatedly, our study highlights the importance to account for different forms of overconfidence when designing incentives for innovation. Researchers have started to analyze this interaction in other domains. For example, Grubb (2009) shows that individuals who underestimate variance in their own consumption are subject to exploitation by contractors and Spinnewijn (2010) analyzes the consequences of different forms of overconfidence in job search on optimal unemployment insurance. Most important for our context, Larkin and Leider (2012) provide experimental evidence that overoptimistic agents sort into convex incentive contracts. Combined with our own findings this latter result suggests that the provision of convex incentive schemes will be particularly effective in promoting innovation. If individual provision of innovative effort is otherwise suboptimally low, institutions that provide convex incentives, such as patenting institutions, may therefore be welfare enhancing.

Finally, our paper also makes a methodological contribution. Existing work on individual determinants of initiative, creativity and innovation at the workplace mostly relies on questionnaire methods (see Bateman and Crant, 1993; Morrison and Phelps, 1999; Parker, 1998), and interviewing techniques (see Frese et al., 1996). While the correlational evidence obtained in these studies yields useful insights, there is also a natural concern that relying on truthful self-reporting of employees may be problematic, because employees may strategically misrepresent the truth. An additional difficulty is that eliciting personality characteristics using questionnaires or interviewing methods does not provide the researcher with a behavioral measure of innovative activity, so that studying policies or the impact of institutions on innovative activity is difficult. Our approach relies on an incentivized laboratory task that we validate using external data, and therefore provides an attractive and incentive compatible alternative which may help to overcome such problems in future research.

The paper proceeds as follows: In Section 2, we present the experimental setup that we used to measure innovative activity and both forms of overconfidence at the individual level. In section 3, we formally derive the hypothesized effects of judgmental overconfidence and overoptimism on innovative activities, based on a stylized model of our experimental setup. Section 4 presents the results and section 5 relates our experimental measures to external measures of innovative activity at the workplace. Section 6 concludes.

\section{Experiment}

We set up a laboratory environment that enables us to assess empirically whether overoptimism and judgmental overconfidence have opposing effects on innovative activity at the individual level. Laboratory experiments have the advantage that participants' behavior can 
be observed in a well-defined and tightly controlled environment. In our case we confront each of our participants with an identical innovation task. The task is based on a paradigm developed by Ederer and Manso (2013) and captures the trade-off between exploration and exploitation, which is one of the core elements of innovative decisions. Moreover, our participants go through a series of experimental tests that provide us with standardized proxies for overoptimism, judgmental overconfidence, cognitive abilities and ambiguity aversion. These measures allow us to isolate the separate predictive effects of different forms of overconfidence on individual innovation in a very clean and simple way.

\subsection{The Ice Cream Stand Task}

Our management task consists in operating a virtual ice cream stand for 20 periods. ${ }^{4}$ In every period, participants can change six different variables. Three variables are categorical: The location of the stand (business district, stadium, or school), the flavor of the ice cream, and the ice cream color intensity (light or bright). Participants are free to choose a flavor without explicitly predefined options. ${ }^{5}$ We decided to not provide predefined options to subjects in this category to add a dimension in which subjects have to generate own ideas about what to choose, so that they could not simply apply a trial-and-error routine to predefined options. The other three variables, sugar content, flavor intensity and price, can be chosen continuously.

The profit function is designed such that every location has a unique, profit-maximizing bliss point. For deviations from the location specific optimal choice in color intensity, sugar content, flavor intensity, and price, we use a linear penalty function to reduce the payoff. The impact of flavor on profits is independent of the location. ${ }^{6}$ Subjects do not know the profit functions. However, as part of the instructions they receive a letter from a fictional previous manager of the stand. The previous manager describes the business strategy he used while selling ice cream in the business district. He mentions that he sold ice cream with orange flavor, he lists flavor intensity, sugar content, and the price that he applied, and he also reveals that he had chosen a light ice cream color. The manager further reveals that he

\footnotetext{
${ }^{4}$ Our task is a modified and extended version of the innovation experiment developed by Ederer and Manso (2013). We are grateful to the authors for providing us with their original experimental code.

${ }^{5}$ In total, 65 different flavors are predefined and coded in the background. If a participant chooses a non-predefined flavor, he or she is asked to pick another flavor.

${ }^{6}$ In Appendix $\mathrm{C}$ we show location specific bliss points and maximally achievable profits at each location in table C.1 and the penalty factors associated with a deviation of one unit in table C.2. The factors for the different flavors are based on real sales numbers in Germany in 2008 provided by "E.I.S. Eis Infoservice der deutschen Markeneishersteller" (see table C.3). To prevent an immediate clustering on obvious choices, we exclude the four most prominent flavors (chocolate, vanilla, strawberry and chocolate chip). The instructions explicitly inform participants that offering these four flavors is never profitable, because they are already offered by successful competitors in all locations.
} 
has tried several combinations of variables in the business district, and he emphasizes that he has never changed the flavor of the ice cream nor the location. Finally, he also mentions the per-period profit he realized using this business strategy. In addition to the details about his own business strategy, the previous manager also provides general information about the business, explaining that the effect of flavor on per-period profits is independent of the location and that different locations may require very different strategies.

The participants thus face the choice between fine-tuning the business strategy of the previous manager (exploitation) or discovering a completely different, more profitable strategy (exploration). The payoffs of the game are defined such that the potential additional profits from fine-tuning the previous manager's strategy in the business district are small. The only sizeable increase in profit in the business district can be achieved by changing the flavor. On the other hand, changing the location to the school, the most profitable location, requires large changes in at least two other variables to obtain a per-period profit which reaches the level of the default business strategy.

During the experiment subjects receive feedback which helps them to learn about the profitability of different strategies. First, they are informed about the profit they obtain at the end of every period. Second, they are also given a customer reaction that contains information about the optimality of their choices. In particular, they receive a binary feedback with regard to one randomly chosen continuous choice variable. ${ }^{7}$ To facilitate learning and to allow for systematic exploration, subjects also receive a table in which they can take notes about their choices, profits, and feedback in each period. The subjects are compensated according to a so-called "exploration contract" which has been shown to be effective in motivating innovative behavior (Ederer and Manso, 2013). Hence, they were not paid for their performance in periods 1-10, but received the acquired profits in periods 11-20.

The ice cream task allows us to observe the extent to which subjects engage in exploratory activities. We focus on four measures of innovative activity in the ice cream stand task: First, a measure for a subject's exploratory behavior is the length of an exploratory phase. Ederer and Manso (2013) define a period as exploratory if a participant is actively exploring novel business strategies, and not simply fine tuning a particular business strategy. The exploratory phase is the longest consecutive number of periods in which a subject engages in exploration. ${ }^{8}$ In addition, we observe the realized profit in the final period of the exploratory

\footnotetext{
${ }^{7}$ For example, if the computer randomly selects the sugar content as the feedback variable and the subject has chosen a sugar content that is above the optimal level for the chosen location, the feedback takes the form: "Many of your customers tell you that the ice cream is too sweet". The subjects only receive feedback of this sort for the continuous variables.

${ }^{8} \mathrm{An}$ exploratory phase is entered if a subject for the first time chooses a location that differs from the location chosen by the previous manager, changes the color or the flavor of the ice cream, or makes a substantial change in one of the three continuous variables. An exploratory phase ends if a participant
} 
phase, i.e., the profit level that a subject considered sufficient to end the exploration process. Second, the average subject specific standard deviation of the business strategy choices in the three continuous variables, price, flavor intensity and sugar content, is indicative of the exploratory behavior of a subject. Achieving high profits at locations other than the business district requires radically altering choices in these three categories. Average subject specific standard deviations are a direct measure of the extent to which a participant engaged in exploration within these variables. Third, we analyze exploration behavior in the flavor dimension, in which subjects had to come up with own ideas. The degree of exploration

in this category measures the extent to which a subject generates ideas about potentially profitable business strategies. Fourth, we also analyze subjects' willingness to invest into exploration by measuring how extensively they take notes. ${ }^{9}$

In every experimental session, subjects first completed the ice cream task and then participated in additional experiments to measure individual preferences, abilities and behavioral biases. We collected proxies for judgmental overconfidence, overoptimism, intelligence and ambiguity aversion. The experimental elicitation of these measures is described in the following subsection.

\subsection{Additional Experimental Measurements}

To measure judgmental overconfidence, we adopt the confidence interval elicitation procedure of Biais et al. (2005), which is originally based on Lichtenstein et al. (1982). In this task participants are asked to provide an upper and a lower limit such that they are 90 percent confident that the correct answer falls between the two. This is repeated for 10 different questions (see Appendix D). Correct answers are not incentivized, which is the standard procedure for this task. Judgmentally overconfident participants typically provide too narrow ranges, so that actual values fall outside the range more than 10 percent of the time.

We use the number of questions for which the true answers fall outside the stated range as a proxy for judgmental overconfidence in our analysis. ${ }^{10}$ In our sample the average number of

stops making such substantial changes in the product mix. To test the robustness of our results, we defined different thresholds that determine whether a change in one of the continuous variables counts as substantial. The threshold that we use is set to a change of at least .25 units in at least one of the variables. Changing this threshold does not qualitatively change our results. Our measure of an exploratory phase differs from that in Ederer and Manso (2013). They require a change in location for an exploratory phase to start and returning to the default location ends the exploratory phase. Again, changing this measure and using the exact definition from Ederer and Manso (2013) does not qualitatively change any of our results.

${ }^{9}$ While taking notes is not of particular importance for a subject who fine-tunes a business strategy, it is essential for a subject who chooses to explore and who radically alters the business strategy. Therefore, the extent to which a subject took notes during the experiment is indicative of his/her overall inclination to explore.

${ }^{10}$ Evidence for the stability of individual differences in judgmental overconfidence has been provided by 
answers outside the confidence interval was 5.9. This shows that our participants exhibited overconfidence in their judgment. ${ }^{11}$ The standard deviation across subjects is 1.94 , indicating substantial variation in the degree of judgmental overconfidence.

We operationalize overoptimism as people's expectations about their own absolute performance in the Raven Progressive Matrices test (Raven et al., 2003). The Raven Progressive Matrices test is a so-called "culture-free" IQ test because it does not depend heavily on verbal skills or other knowledge explicitly taught during formal education. The test consists of 12 items, each of which presents a pattern of abstract figures. For each item, the test taker must choose the part out of 8 predefined solutions that correctly completes the pattern. Our participants first have to correctly solve two training patterns before each subject is given a total of 12 minutes to complete twelve different patterns without any feedback. After having completed the task subjects are asked to guess the number of patterns that they have solved correctly.

We use the difference between the guessed number of correctly solved patterns and the actual number of correctly solved patterns as a proxy for an individual's overoptimism. The performance in the IQ test itself serves as a control variable for an individual's cognitive abilities. In line with the usual methodology in this task, individuals are neither paid for their performance in the task, nor for the accuracy of their expectations. On average, our subjects accurately predict the number of correctly solved patterns in the Raven Progressive Matrices test (mean overoptimism is -0.05 ). However, the standard deviation in overoptimism across subjects is 1.93 , indicating substantial variation between subjects. Moreover, we find that our measures of judgmental overconfidence and overoptimism are slightly negatively correlated $(\rho=-0.2, p=0.01)$.

Finally, subjects participate in a separate lottery experiment in which we elicit each subjects' ambiguity aversion. ${ }^{12}$ Instructions for the elicitation procedure can be found in appendix E.

\subsection{Procedures and Subject Pool}

We recruited 119 subjects from a subject pool that includes students of the University of Zurich and the Swiss Federal Institute of Technology (ETH). In addition to our student

Klayman et al. (1999), Parker and Fischhoff (2005) and Jonsson and Allwood (2003)

${ }^{11}$ This result is comparable to Russo and Schoemaker (1992), who found proportions between 58 percent and 38 percent of true answers falling outside the stated range for business managers, and Biais et al. (2005), who find a proportion of 64 percent for students in London and Toulouse.

${ }^{12}$ We also elicited subjects' loss and risk aversion. Controlling for these measures does not alter any of our results. As our task is characterized by ambiguity, we decided to focus on ambiguity aversion and excluded the other two measures from our analysis. 
participants we also invited 35 middle managers of a financial industries company with approximately 550 employees to participate in our experiment. All experimental sessions (including the ones with the managers) were conducted in the laboratory of the University of Zurich. The experiments were computerized with the software z-tree (Fischbacher, 2007). Student data was collected in 4 sessions in October 2009 and June 2010. The managers participated in three sessions in November and December 2009. A session lasted, on average, 90 minutes. During the experiment, experimental currency units called Taler were used to keep track of monetary earnings. The exchange rate was set at 75 Taler $=$ CHF 1 . Subjects on average earned CHF 37 (approx. USD 37) during the experiment. ${ }^{13}$

\section{Theoretical Analysis and Hypotheses}

In this section we theoretically analyze a stylized version of the exploration-exploitation trade-off which is central in our experimental setup. This allows us to formally derive a set of testable hypotheses which will help to organize our data analysis.

\subsection{Assumptions}

We consider an agent $i$ who faces a finite time horizon of $T$ periods and discounts the future at a rate of $\delta$. In every period the agent needs to implement a business strategy. The agent always has the possibility to either exploit an existing or to explore and to implement a novel business strategy. We represent the per-period utility that results from implementing a particular business strategy in period $t$ by $\omega$. We assume that the agent faces an "exploration contract" as defined by Ederer and Manso (2013), i.e., the agent receives the per-period implementation utility only in the periods $\bar{t}<t \leq T$ (the compensation phase), while he is not rewarded for his activities in the periods $t \leq \bar{t}$ (the non-compensation phase). ${ }^{14}$

If an agent decides to explore in period $t$, he implements a novel business strategy $\omega_{t}$ which is drawn from an agent specific distribution $F\left(\omega, \mu_{i}, \sigma_{i}\right)$, where $\mu_{i}>0$ is the mean and $\sigma_{i}$ is

\footnotetext{
${ }^{13}$ Student subjects were drawn from a database of volunteers using ORSEE (Greiner, 2004). The number of participants differed across sessions. However, all experiments were purely individual decision experiments, so session size should not influence the results. 17 subjects participated in the first student session in October 2009 , and the exchange rate was set to 100 Taler $=$ CHF 1 . Moreover, subjects in this session received a show-up fee of CHF 10. In all other sessions the show-up fee was set to 0 and the exchange rate was set to 75 Taler $=$ CHF 1 . We don't find any significant differences in behavior in the first session, and therefore pool the data in the analysis. 102 student subjects participated in sessions in June 2010. The tables in which subjects could take notes were only systematically collected for these student subjects and not during the 2009 sessions.

${ }^{14}$ As explained in the previous section the intuition behind the effectiveness of such a contract in fostering innovation is that the contract tolerates early failure, but rewards late success.
} 
the standard deviation of agent i's strategy distribution. We assume that $F$ is differentiable and has support on the whole real line. Differences in $\mu_{i}$ and $\sigma_{i}$ can be interpreted as differences in an agents' ability and precision in generating ideas for new business strategies. It is assumed that draws from $F$ are iid. ${ }^{15}$

If an agent decides to exploit in period $t$, he implements the best business strategy currently available to him $\left(\omega_{t}^{m}=\max _{t}\left\{\omega_{t}\right\}\right)$ and fine-tunes it based on the market feedback that he receives. We assume that fine-tuning improves the business strategy somewhat so that exploitation implies that the per-period utility of the strategy in the next period increases to $\omega_{t+1}^{m}=\omega_{t}^{m}+\epsilon$. We assume that the value increase induced by exploitation is small. In particular, we impose the upper limit $\epsilon \leq \int_{\mu}^{\infty} f(\omega)(\omega-\mu) d \omega$. This restriction implies that the expected value increase from exploration is larger than the one from exploitation as long as the best available idea is equal to or worse than the mean of the distribution. ${ }^{16}$

\subsection{Optimal Behavior}

We start by showing how an agent $i$ who in period $t$ faces the choice between fine-tuning the best business strategy currently available to him $\left(\omega_{t}^{m}\right)$ and drawing a novel business strategy $\omega_{t}$ from the distribution $F\left(\omega, \mu_{i}, \sigma_{i}\right)$ optimally behaves: ${ }^{17}$

Lemma 1 (Stopping Rule) An agent $i$ facing a distribution of business strategies $F\left(\omega, \mu_{i}, \sigma_{i}\right)$ will explore a novel business strategy $\omega_{t}$ in period $t$ if the best available business strategy $\omega_{t}^{m}$ is strictly inferior to his period-dependent threshold strategy $\bar{\omega}_{t}$. Otherwise, agent $i$ will exploit and implement $\omega_{t}^{m}$. The period-dependent threshold strategy $\bar{\omega}_{t}$ is always (weakly) superior to $\mu_{i}$, is constant in the non-compensation phase $(t \leq \bar{t})$, and is strictly decreasing in the compensation phase $(t>\bar{t})$. Thus, if the agent stops exploring and starts exploiting in period $t$, he will also exploit in all later periods $t^{\prime}>t$.

\section{Proof: See Appendix A.}

The behavior described in the Lemma is intuitive. Because the benefits of fine-tuning a strategy are limited, exploration is always optimal, as long as the best available business

\footnotetext{
${ }^{15}$ By assuming that the distribution $F$ remains constant over time, we abstract from learning effects. This greatly simplifies the analysis and as long as the updating process itself is not affected by overconfidence, the consideration of learning would not alter our results.

${ }^{16}$ We impose this restriction to rule out unrealistic cases in which exploitation is favored over exploration even if the immediate payoff from exploitation $\left(\omega^{m}\right)$ is less than the immediate expected payoff from exploration $(\mu)$. This could be possible if $\epsilon$ is very large so that the exploitation strategy creates larger increases in the continuation value than the exploration strategy.

${ }^{17}$ The best business strategy available to the agent in period $1\left(\omega_{1}^{m}\right)$ can either be thought of as a default business strategy or there may not be a best business strategy at all (which is identical to assuming that $\left.\omega_{1}^{m}=-\infty\right)$.
} 
strategy is strictly inferior to the mean of the agent's strategy distribution. The reason is that exploration not only yields a higher expected per-period utility in the current period $\left(\mu>\omega_{t}^{m}\right)$, but also promises a larger improvement in the best available strategy $\left(\int_{\mu}^{\infty} f(\omega)(\omega-\right.$ $\mu) d \omega>\epsilon, \forall \omega_{t}^{m}<\mu$, see our assumption above). Thus, irrespective of whether the agent is compensated in a particular period or not, exploration is superior to exploitation if the best available idea is below the mean of the agent's idea distribution.

In the non-compensation phase $(t \leq \bar{t})$, the goal is to search for a strategy such that the continuation value as of period $\bar{t}+1$ is maximized. In this phase the agent faces the following trade-off: he can either exploit which increases the per-period utility of his best available idea by $\epsilon$ with certainty (fine-tuning) or he explores, which has the benefit that he may find a significantly better new strategy, but also entails the risk that he makes no progress at all. There is exactly one strategy $\bar{\omega}$ for which the constant increase $\epsilon$ exactly equals the expected value increase from exploration. Because there are no immediate payoff consequences and the agent solely focuses on the continuation value in period $\bar{t}+1$, this threshold strategy remains identical across all periods in the non-compensation phase.

In the compensation phase $(t>\bar{t})$, the decision trade-off becomes more complicated. Once the utility of the best available business strategy surpasses $\mu$, exploration implies an immediate cost, because the expected per-period utility of the newly drawn business strategy is lower than the per-period utility of the best strategy already available to the agent. However, exploration also offers the agent the chance of drawing a business strategy which is superior to the best strategy available to him so far, and if this happens, he not only benefits in the current period, but also in all future periods. Obviously, the agent's incentive to engage in exploration is decreasing in the value of the best available business strategy. If the best available strategy is already very good, the immediate cost of exploration is high and the probability that the agent discovers an even better idea from which he can benefit in the future is small. In addition, it is important to notice that the benefits of exploration (given a certain best strategy which is already available) decrease over time. The reason is that a shorter time horizon lowers the benefit of having a new best idea. This implies that the threshold strategy at which the agent switches from exploration to exploitation is decreasing over time in the compensation phase.

\subsection{Effects of Overoptimism and Judgmental Overconfidence}

Previous work indicates that many people exhibit two distinct forms of overconfidence. On the one hand, people tend to be overoptimistic regarding their abilities (see, e.g., Svenson, 1981; Dunning et al., 1989; Alicke et al., 1995). On the other hand, people often overestimate 
their precision, i.e., they are judgmentally overconfident (see, e.g., Lichtenstein et al., 1982; Russo and Schoemaker, 1992). Our formalization allows us to capture both behavioral biases in a natural way. We assume that the agent has imprecise information about $\mu_{i}$ and $\sigma_{i}$, i.e., he forms subjective beliefs $\hat{\mu}_{i}$ and $\hat{\sigma}_{i}$ which may deviate from the true mean and standard deviation of the agent's distribution.

An agent is overoptimistic if $\hat{\mu}_{i}>\mu_{i}$. In this case he is overconfident regarding his ability in generating ideas, i.e., he overestimates the average quality of his ideas. ${ }^{18}$ To isolate the effect of overoptimism, we model overoptimism as a translation of the whole probability density function to the right, such that all moments of the distribution other than the mean are unaffected by overoptimism.

We say that an agent is judgmentally overconfident if $\hat{\sigma}_{i}<\sigma_{i}$. Judgmental overconfidence implies that the agent overestimates his precision in generating ideas, i.e., he underestimates the variance of the distribution from which he draws ideas. We assume that judgmental overconfidence leads to a simple mean preserving reduction of variance as it is defined in Diamond and Stiglitz (1974). That is, we assume that density is shifted from the tails towards the mean of the distribution. As a consequence, an agent behaves according to his perceived idea distribution function $F\left(\omega, \hat{\mu}_{i}, \hat{\sigma}_{i}\right)$, while ideas are actually drawn from the true idea distribution function $F\left(\omega, \mu_{i}, \sigma_{i}\right)$.

We are interested in how overoptimism and judgmental overconfidence affect the trade-off between exploration and exploitation. To analyze these effects we need to investigate how the agent's distorted beliefs about the distribution of his ideas affect the period-dependent thresholds $\bar{\omega}_{t}$. Misperceptions in $\mu_{i}$ and $\sigma_{i}$ that raise $\bar{\omega}_{t}$ lead to an inefficiently long exploration phase, whereas misperceptions that lower $\bar{\omega}_{t}$ cause an inefficiently short exploration phase.

Proposition 1 (Effect of Judgmental Overconfidence) The period-dependent stopping thresholds $\bar{\omega}_{t}$ for an agent who is judgmentally overconfident regarding the variance of the quality of his ideas $\left(\hat{\sigma}_{i}<\sigma_{i}\right)$ are too low $\left(\frac{\partial \bar{\omega}_{t}}{\partial \sigma_{i}}>0\right)$. This implies that a judgmentally overconfident agent will, on average, explore fewer novel strategies than would be optimal given the true distribution of his business strategies.

Proof: See Appendix A.

The intuition behind the negative effect of judgmental overconfidence on innovation is the following: the fact that judgmentally overconfident people underestimate the variance of their idea distribution implies that they in particular underestimate the upward potential

\footnotetext{
${ }^{18}$ Dubra (2004) analyzes a related form of overoptimism in a different search context.
} 
of exploration. The reason is that they assign too little probability weight to very valuable ideas. ${ }^{19}$ The immediate cost of exploration (in the compensation phase), on the other hand, remains unaffected by judgmental overconfidence. As a consequence, judgmentally overconfident people terminate the exploration process sooner than they should.

Proposition 2 (Effect of Overoptimism) The period-dependent stopping thresholds $\bar{\omega}_{t}$ for an agent who is overoptimistic regarding the average quality of his ideas $\left(\hat{\mu}_{i}>\mu_{i}\right)$ is too high $\left(\frac{\partial \bar{\omega}_{t}}{\partial \mu_{i}}>0\right)$. This implies that an overoptimistic agent will, on average, explore more novel strategies than would be optimal given the true distribution of his business strategies.

Proof: See Appendix A.

Intuitively, the positive effect of overoptimism on innovation can be explained as follows: overoptimistic decision makers have a biased view of their distribution of ideas in the sense that they think that the distribution lies more to the right than it actually does. This shifted perception has two effects with regard to the trade-off implied by exploration: on the one hand, an overoptimistic agent underestimates the immediate cost of exploration (in the compensation phase), because he perceives the expected per-period utility of exploration as higher than it is. On the other hand, the agent also overestimates the upward potential of exploration as he puts too much probability weight on very valuable ideas. Both these effects push in the same direction and imply that overoptimistic people engage longer in the exploration process than they should.

Proposition 1 and 2 establish that, in our model, the two different forms of overconfidence, overoptimism and judgmental overconfidence, have opposing impacts on an agent's decision to explore or to exploit. Overoptimism, an overestimation of average ability in idea generation, unambiguously leads to excessive exploration. On the other hand, judgmental overconfidence, an underestimation of the variance of the idea generation process, unambiguously leads to too little exploration.

The inefficiencies caused by overoptimism and judgmental overconfidence are also reflected in the realized profits of the agent's innovative activities:

Corollary 1 The excessive exploration caused by overoptimism harms overall profits of the agent. However, the per-period profit of the ultimately realized idea is increasing in overoptimism. The insufficient exploration caused by judgmental overconfidence, on the other hand, decreases both overall profits and the per-period profit of the ultimately realized idea.

\footnotetext{
${ }^{19}$ Similarly, judgmentally overconfident people also underestimate the downward risk of exploration, by putting too little probability weight on very poor ideas. But since one can always return to $\omega_{t}^{m}$, the underestimation of downward risk has no impact on the stopping threshold, because the decision to explore only depends on the tradeoff between the currently best available idea, the upward potential of exploration relative to that idea, and the costs of exploration.
} 
The Corollary is intuitive. The Lemma identifies a unique profit maximizing business strategy: the agent should explore novel business strategies until he reaches a period in which the per-period utility of the best business strategy already available to him surpasses a period-dependent threshold utility. From this period on the agent should exploit this business strategy and implement it in all remaining periods. Propositions 1 and 2 show that both overoptimism and judgmental overconfidence induce the agent to deviate from this profit maximizing strategy. Hence, both these biases decrease overall profits of the agent. However, the fact that overoptimism increases the period-dependent stopping thresholds $\bar{\omega}_{t}$ also implies that the agent explores more business strategies than in the absence of the bias. Accordingly, an overoptimistic agent will, on average, end up implementing better business strategies than an unbiased, but otherwise identical agent.

\subsection{Hypotheses}

The formal analysis of the stylized model of our experiment yields the following hypotheses that we can test using our experimental data:

Hypothesis 1 (Judgmental Overconfidence) In our experiment, a higher degree of judgmental overconfidence is hypothesized to lead to less exploratory activity. In particular, subjects with high judgmental overconfidence are expected to have lower stopping thresholds, and consequently a shorter exploratory phase. Moreover, they are expected to have a lower variance in product mix choices and to explore less ice cream flavors. In addition, a higher level of judgmental overconfidence is also expected to decrease a subject's propensity to take systematic notes about the results of his or her exploratory activities. Finally, we expect that the inefficiently low exploration leads to smaller total and maximum per-period profits.

Intuitively, judgmentally overconfident subjects believe that they have pinned down the potential profits in the task relatively precisely. Controlling for other subject characteristics, this form of overconfidence reduces the believed profitability of exploration, which we expect to observe in our experimental data.

Hypothesis 2 (Overoptimism) In our experiment, a higher degree of overoptimism is hypothesized to lead to more exploratory activity. In particular, subjects with high overoptimism are expected to have higher stopping thresholds, and consequently a longer exploratory phase. Moreover, they are expected to have a higher variance in product mix choices, and to explore more ice cream flavors. A higher level of overoptimism is also expected to manifest itself in an increase of a subject's propensity to take notes. Finally, we expect that the inefficiently high exploration leads to smaller total, but higher maximum per-period profits. 
Intuitively, overoptimistic subjects overestimate the expected profitability of novel ideas. This biases them towards excessive exploration. Excessive exploration is expected to increase the profitability of the best available idea at the end of the experiment. However, the additional gross revenues are outweighed by the costs caused by excessive exploration, which reduces expected total profits.

\section{Results: Effects of Overoptimism and Judgmental Overconfidence}

In this section we show to what extent our measures of judgmental overconfidence and overoptimism predict innovative behavior in the experimental management task that we have implemented. Proposition 1 predicts that judgmental overconfidence decreases exploratory activity and the Corollary implies that the reduction in innovation harms per-period profits. Our data yield the following result:

Result 1 (Judgmental Overconfidence) Judgmental overconfidence is associated with a significant reduction in explorative and innovative activity and negatively affects the average earnings as well as the maximum per-period profit in the ice cream task.

Support for Result 1 comes from Figure 1 and Table 1. In Figure 1 we split our sample of participants at the median level of judgmental overconfidence and present our four measures of innovative activity for people with high and low levels of judgmental overconfidence. The figure reveals that subjects exhibiting a higher level of judgmental overconfidence have shorter exploratory phases (two sample t-test: $p=0.015$ ), are less likely to take comprehensive notes of explored business strategies $(p=0.001)$, and have a smaller average individual standard deviation in their choices of the three continuous strategic variables in the ice cream task $(p=0.023)$. Although judgmentally overconfident subjects also try out a smaller number of flavors, this difference is not statistically significant $(p=0.123)$.

Table 1 confirms the results illustrated in Figure 1 using regression analysis. Column (1) shows the marginal effects of a Poisson estimation, in which we regress the length of the exploratory phase on judgmental overconfidence, overoptimism, and control variables for IQ, ambiguity aversion, and being part of the student subject pool. We use a Poisson model because the length of the exploratory phase is a variable counting the number of periods in which a subject keeps exploring the product mix before turning towards fine tuning. We

find a highly significant negative association between judgmental overconfidence and the 
Figure 1: Median Splits
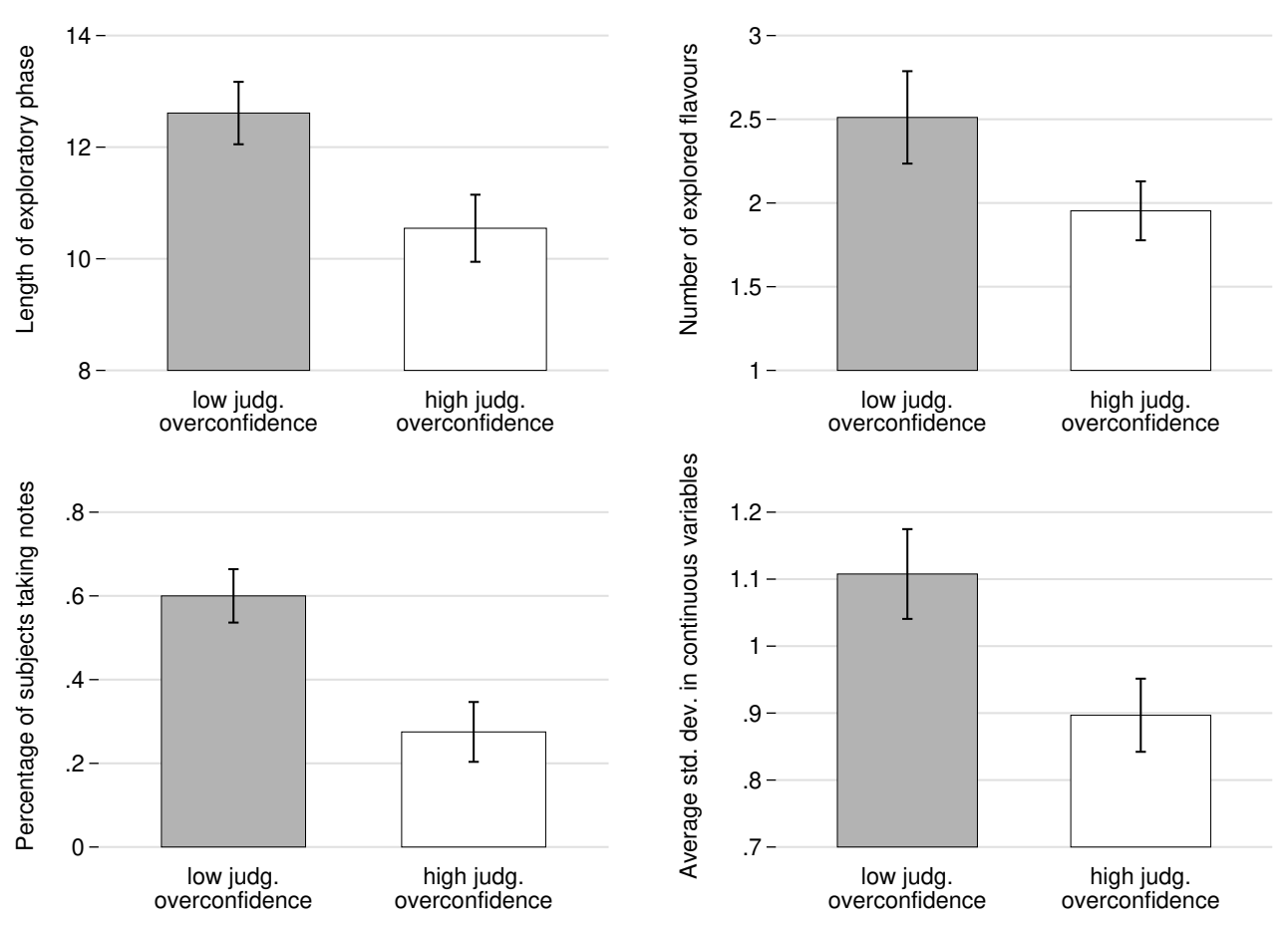

The sample is split in two halves at median judgmental overconfidence. The top left figure shows a median split for the length of the exploratory phase. The top right figure shows a median split for the number of explored flavors. The bottom left figure shows a median split for the frequency of completed notes. The bottom right picture shows a median split for the average standard deviation in the continuous variable choices of the product mix.

length of the exploratory phase. Per unit increase in the subject's degree of judgmental overconfidence, a subject stops exploring 0.47 periods earlier. ${ }^{20}$

In addition to stopping exploring earlier, our data also confirms our theoretical prediction with respect to subjects' stopping thresholds. Column (2) reports the coefficients of a robust regression on the profit of a subject in the last period of the subject's exploratory phase. ${ }^{21}$ The regression confirms that judgmentally overconfident subjects have lower stopping thresholds. Per unit increase in a subject's degree of judgmental overconfidence, the stopping threshold is reduced by 10.4 points.

\footnotetext{
${ }^{20}$ As already pointed out in section 2 , this result is robust with respect to changes in the definition of an exploratory phase. Requiring a change in flavor or in location as a starting point of an exploratory phase, or changing the threshold at which changes in the continuous variables no longer count as exploratory does not qualitatively change the result.

${ }^{21}$ In columns (2), (5), (6) and (7) of table 1, we use robust regressions because our data contains a number of outliers.
} 
In column (3) we use a Poisson regression to examine the effect of judgmental overconfidence on the number of different ice cream flavors that a subject explored over the course of the experiment. We find that overconfidence in judgment is associated with a highly significant reduction in the number of explored flavors. Per unit increase in the subject's degree of judgmental overconfidence, the number of explored flavors on average decreases by 0.17.

Column (4) reports the marginal effects of a probit regression on a dummy that indicates whether or not a subject took comprehensive notes of explored business strategies and the associated profits. Taking notes is an indicator of the effort that subjects invested in exploring. We hypothesized that a judgmentally overconfident subject is less willing to explore, and therefore should be less willing to invest effort in exploratory activities, like taking notes. This is also what we find in the data. Indeed, it becomes $7.6 \%$ less likely that a subject took comprehensive notes during the experiment per unit increase in the subject's degree of judgmental overconfidence.

In column (5) we investigate the association between judgmental overconfidence and the average individual standard deviation in the choice of the continuous strategic variables (price, flavor intensity and sugar content) in the experiment. Using a robust regression we find that judgmental overconfidence is negatively associated with the average standard deviation, indicating that overconfidence reduces the degree of exploration within these variables. In contrast to the result based on the median split in Figure 1, this result is, however, not significant $(p=0.25)$. This regression also reveals that our student sample is slightly less explorative in this domain than our manager sample.

Finally, columns (6) and (7) examine how judgmental overconfidence affects per-period profits of participants in the ice cream stand task. Our theory predicts that insufficient exploration should ultimately lead to a reduction in achieved as well as maximum per-period profits. We present the results of robust regressions of achieved earnings and maximum per-period profits on our explanatory variables. The regression estimates indeed reveal a negative relationship between judgmental overconfidence and performance in the task. The coefficients of judgmental overconfidence are large and significant at the 10 percent level. Per unit increase in the subject's degree of judgmental overconfidence, total profits in the ice cream task decrease by 79 points $(p=0.055)$ and the maximum per-period profit decreases by $9.3(p=0.053)$ points.

Taken together, the evidence presented in Figure 1 and Table 1 reveals a clear and consistent picture of the predictive effects of judgmental overconfidence on individual innovation. The evidence shows that the tendency to overestimate the precision of one's information is detrimental to innovative activity, reduces explorative efforts and leads to lower profits. This provides strong support for our theoretical predictions on judgmental overconfidence stated 
Table 1: Regression Analysis of Measures for Innovative Activity on Covariates

\begin{tabular}{|c|c|c|c|c|c|c|c|}
\hline & $\begin{array}{c}(1) \\
\text { Expl. } \\
\text { Phase }\end{array}$ & $\begin{array}{c}(2) \\
\text { Stop. } \\
\text { Thres- } \\
\text { hold }\end{array}$ & $\begin{array}{c}(3) \\
\# \text { of } \\
\text { expl. } \\
\text { flavors }\end{array}$ & $\begin{array}{c}(4) \\
\text { Notes }\end{array}$ & $\begin{array}{l}\text { (5) } \\
\text { Avg. } \\
\text { Std. } \\
\text { Dev. }\end{array}$ & $\begin{array}{c}(6) \\
\text { Total } \\
\text { Profit }\end{array}$ & $\begin{array}{c}(7) \\
\text { Max. } \\
\text { Period } \\
\text { Profit }\end{array}$ \\
\hline IQ & $\begin{array}{r}0.23 \\
(0.17)\end{array}$ & $\begin{array}{l}-0.25 \\
(4.84)\end{array}$ & $\begin{array}{l}-0.07 \\
(0.07)\end{array}$ & $\begin{array}{r}0.03 \\
(0.03)\end{array}$ & $\begin{array}{r}0.02 \\
(0.03)\end{array}$ & $\begin{array}{l}-1.36 \\
(45.8)\end{array}$ & $\begin{array}{l}-2.75 \\
(5.34)\end{array}$ \\
\hline $\begin{array}{l}\text { Over- } \\
\text { opt. }\end{array}$ & $\begin{array}{r}0.12 \\
(0.19)\end{array}$ & $\begin{array}{l}-3.96 \\
(5.35)\end{array}$ & $\begin{array}{c}0.18^{* *} \\
(0.07)\end{array}$ & $\begin{array}{r}0.01 \\
(0.04)\end{array}$ & $\begin{array}{r}0.03 \\
(0.03)\end{array}$ & $\begin{array}{l}-28.3 \\
(50.6)\end{array}$ & $\begin{array}{l}-2.56 \\
(5.91)\end{array}$ \\
\hline $\begin{array}{l}\text { Judg. } \\
\text { OC. }\end{array}$ & $\begin{array}{l}-0.47^{* * *} \\
(0.15)\end{array}$ & $\begin{array}{l}-10.4^{* *} \\
(4.33)\end{array}$ & $\begin{array}{l}-0.17^{* * *} \\
(0.06)\end{array}$ & $\begin{array}{l}-0.08^{* *} \\
(0.03)\end{array}$ & $\begin{array}{l}-0.03 \\
(0.02)\end{array}$ & $\begin{array}{l}-79.3^{*} \\
(40.9)\end{array}$ & $\begin{array}{l}-9.31^{*} \\
(4.78)\end{array}$ \\
\hline Student & $\begin{array}{l}-0.01 \\
(0.68)\end{array}$ & $\begin{array}{l}-0.47 \\
(19.4)\end{array}$ & $\begin{array}{l}-0.24 \\
(0.29)\end{array}$ & & $\begin{array}{l}-0.19^{*} \\
(0.11)\end{array}$ & $\begin{array}{r}38.5 \\
(183)\end{array}$ & $\begin{array}{r}7.86 \\
(21.38)\end{array}$ \\
\hline $\begin{array}{l}\text { Amb. } \\
\text { Av. }\end{array}$ & $\begin{array}{l}-0.03 \\
(0.35)\end{array}$ & $\begin{array}{l}-1.59 \\
(9.92)\end{array}$ & $\begin{array}{c}0.27^{*} \\
(0.14)\end{array}$ & $\begin{array}{r}0.04 \\
(0.07)\end{array}$ & $\begin{array}{l}-0.02 \\
(0.06)\end{array}$ & $\begin{array}{l}-35.7 \\
(93.8)\end{array}$ & $\begin{array}{r}-1.54 \\
(10.95)\end{array}$ \\
\hline Cons. & & $\begin{array}{l}231.5^{* * *} \\
(68.7)\end{array}$ & & & $\begin{array}{l}1.20^{* * *} \\
(0.38)\end{array}$ & $\begin{array}{l}2262^{\text {*** }} \\
(649)\end{array}$ & $\begin{array}{l}265.09^{* * * *} \\
(75.84)\end{array}$ \\
\hline Obs. & 151 & 151 & 151 & 98 & 151 & 151 & 151 \\
\hline
\end{tabular}

Columns (1) and (3) report marginal effects of Poisson regressions on count data. Column (4) shows marginal effects of a probit regression. Columns (2) and (5)-(7) show coefficients of robust regressions. Student is a dummy variable for the student subsample. Amb. Av. is our measure of ambiguity aversion. Standard errors are reported in parentheses. Significance levels: ${ }^{*} \mathrm{p}<0.1,{ }^{* *} \mathrm{p}<0.05,{ }^{* * *} \mathrm{p}<0.01$. Subjects that made inconsistent choices in the ambiguity aversion task are excluded. Inclusion of these subjects does not qualitatively change the result. Data on notes is only available for student subjects participating in experiments in 2010, which reduces the sample size to 98.

in Proposition 1 and the Corollary.

Regarding the effect of overoptimism on exploratory activities and profits, Proposition 2 and the Corollary suggest that overoptimism increases innovative activity, decreases total earnings due to over-exploration, but increases the maximum per-period profit that a subject achieves during the experiment. Our data yield the following result:

Result 2 (Overoptimism) Overoptimism is associated with an increase in the number of explored flavors, the length of the exploratory phase, the average standard deviation of product mix choices and the tendency to take comprehensive notes in the ice cream task. However, 
this positive relationship is only statistically significant for the number of explored flavours. Moreover, overoptimism neither significantly affects the stopping threshold, nor total profits or the maximum per-period profit in our experiment.

An inspection of the estimations presented in Table 1 reveals that our measure of overoptimism is positively related to all four exploration measures, but affects only one of them significantly. Column (3) shows that per unit increase in a subject's degree of overoptimism, the number of explored flavors increases by 0.18 units. Besides this, overoptimism does not significantly affect our measures of exploratory activity. Hence, we cannot reject the hypothesis that overoptimism has no effect on exploratory behavior in our setup. In column (2) we also find no evidence that overoptimism is related to the stopping threshold. In addition, there is no evidence for a link between overoptimism and profits. The regressions for total earning and maximum per-period profits in columns (6) and (7) do not yield significant results for the overoptimism variable.

In light of the existing field data the lack of a strong impact of overoptimism on innovative activity in our data is somewhat surprising. In particular, Galasso and Simcoe (2011) find a robust correlation between CEO overconfidence and innovative activities of the company. Even more so, they find that overconfident CEO's obtain more patents and citations per dollar of R\&D. This implies that they are more likely to generate particularly good innovations, but it does not imply that they are more profitable since the measure ignores potential opportunity costs. This is precisely what our model suggests.

The existing field evidence as well as aspects of our data suggest that the failure to find significant correlations between overoptimism and innovative activity in our experiment may be a consequence of our overoptimism measure. Interestingly, the regressions in Table 1 reveal that our IQ measure itself is also not predictive with respect to the innovative activities of our subjects. It is therefore likely that the culture-free intelligence measure that we used is not strongly related to a subject's creativity and explorativeness. It is therefore possible that overoptimism in the domain of culture-free intelligence does not generalize to overoptimism in the domain of creativity and innovative activity. If this is the case, it is not surprising that our proxy for overoptimism, the difference between guessed correct patterns in the Raven's IQ task and the true number of correct patterns in the Raven's IQ task, does not correlate with observed behavior in the ice cream task. The current state of research does not provide much insights regarding more appropriate measures of overoptimism in the context we are interested in. We hope that future research will show how and to what extent different forms of overoptimism correlate across different domains of choices, so that it becomes easier to find a useful measure for the domain one is interested in. 


\section{External Validity of the Experimental Task}

A potential pitfall of a laboratory measure of exploratory activity and innovation is that it is unclear to what extent the measure captures the same type of innovativeness that companies care about. We identify the extent to which our laboratory measure correlates with real-life behavior by comparing the laboratory decisions of our manager participants with external data on their individual innovativeness as well as related measures for performance on the job. To obtain these measures in the company, we sent an online survey to the direct supervisor of each manager participant as well as to a person in the HR department who was familiar with the manager's dossier. ${ }^{22}$

Every manager was rated in five different categories: Taking charge behavior, action orientation, gestalt motivation, creativity, and performance. ${ }^{23}$ "Taking charge" is measured via an established questionnaire from the management literature (Morrison and Phelps, 1999). Taking charge is defined as "constructive efforts by employees to effect functional change with respect to how work is executed". It is measured with a 10-item questionnaire on a 5-point Likert scale and has previously been associated with innovative behavior in the company (see Unsworth, 2001). While taking charge has originally been developed as a pro-active personality and initiative measure, there is convergence to the view that initiative and pro-activity are necessary determinants of innovative activity (see Unsworth and Parker, 2003). We have adapted the items measuring "action orientation" and "gestalt motivation" from the "Bochumer Inventar zur berufsbezogenen Persoenlichkeitsbeschreibung" (Hossiep and Paschen, 2003). ${ }^{24}$ There are 9 items for action orientation and 12 items for gestalt motivation. Both are elicited on a 7-point Likert scale. Persons with high levels of action orientation start implementing ideas as soon as a decision has been made; they are very goaloriented and do not get distracted by obstacles or difficulties when carrying out a project. Gestalt motivation is defined as having a self-starting, pro-active work approach and the motivation to change processes and situations according to one's own agenda. It describes the attitude to actively create and change the environment and organizational processes the employee is involved in. While both, "action orientation" and "gestalt motivation", are more closely linked to the implementation of innovations rather than its exploratory component, we have included them into our questionnaires to measure a broader range of innovative

\footnotetext{
${ }^{22}$ To ensure anonymity, we did not contact the supervisors directly, but through a third agency, which subsequently matched the survey data to the experimental data. This procedure guaranteed that neither we nor the financial industry company can link performance in the experimental task or the rating in the survey to the identity of a manager.

${ }^{23}$ All items used in the survey are reproduced in Appendix D.

${ }^{24}$ Originally, this is a self-report questionnaire. We rephrased the items such that the ratings relate to a third person.
} 
abilities on the individual level. Finally, "creativity" and "performance" were each assessed with a 4 item questionnaire on a 7-point Likert scale. Both of these questionnaires were developed by us. All questions can be found in Appendix D.

We received 31 completed surveys from direct supervisors and 26 surveys from the HR department. $^{25}$ The correlations between the supervisor ratings and the HR-ratings are generally high $(\rho \in[0.46,0.66])$ and significant, with the exception of the action orientation ratings (see table B.3 in Appendix B). Since more data is available for supervisor ratings and since supervisors are, in general, closer to the managers during everyday business, we focus on supervisor ratings in our analysis below. ${ }^{26}$

When investigating the relation between these external measures and our laboratory measure of innovative activity, we find the following result:

Result 3 (External Validity) Profit measures in the ice cream task are strongly correlated with performance, creativity and gestalt motivation measures in the company. The profit measures are also strongly correlated with taking charge behavior.

Table 2: Pairwise Correlations of experimental and external survey measures

\begin{tabular}{lccccc}
\hline \hline & $\begin{array}{c}(1) \\
\text { Creativity }\end{array}$ & $\begin{array}{c}(2) \\
\text { Gestalt } \\
\text { motivation }\end{array}$ & $\begin{array}{c}(3) \\
\text { Action } \\
\text { orientation }\end{array}$ & $\begin{array}{c}(4) \\
\text { Taking } \\
\text { charge }\end{array}$ & $\begin{array}{c}(5) \\
\text { Performance }\end{array}$ \\
\hline Profit Period & $0.33^{*}$ & $0.44^{* *}$ & 0.23 & $0.44^{* *}$ & $0.49^{* * *}$ \\
$11-20$ (Points) & $(0.07)$ & $(0.013)$ & $(0.22)$ & $(0.014)$ & $(0.005)$ \\
Max. Period & $0.34^{*}$ & $0.46^{* * *}$ & 0.28 & $0.46^{* * *}$ & $0.52^{* * *}$ \\
Profit (Points) & $(0.06)$ & $(0.009)$ & $(0.13)$ & $(0.009)$ & $(0.003)$ \\
\hline Observations & 31 & 31 & 31 & 31 & 31 \\
\hline \hline
\end{tabular}

The table reports pairwise correlation coefficients. p-values are reported in parentheses below the correlation coefficient. Significance levels: ${ }^{*} \mathrm{p}<0.1,{ }^{* *} \mathrm{p}<0.05,{ }^{* * *} \mathrm{p}<0.01$.

Support for Result 3 comes from Table 2. The table shows pair-wise correlation coefficients between average and maximum profit measures and the employee ratings in the external surveys. First of all, it is noteworthy that every single correlation coefficient is positive, indicating that performance in the experimental task is directionally consistent with

\footnotetext{
${ }^{25}$ We did not obtain two completed surveys for all of the 35 participating managers, because there was turnover at the company and for some managers no direct supervisor or HR person was available.

${ }^{26}$ In appendix B, we also provide the analysis for pooled ratings. The patterns do not change qualitatively.
} 
all our external measures. Manager creativity is significantly correlated with both profit measures in the ice cream task, subject earnings over the last ten periods in the experiment as well as the maximum per-period profit achieved by a subject throughout the experiment. The same picture arises when looking at gestalt motivation. Both profit measures are highly positively correlated with the reported gestalt motivation (the correlation coefficient is always above 0.4 ) and the correlations are always significant at least at the 5 percent level. The relationship between action orientation and our experimental task is less clear. The correlation coefficients are lower (between 0.2 and 0.3 ), and not statistically significantly different from zero. ${ }^{27}$ When looking at the correlation with taking charge behavior, the performance in the experimental task is again highly predictive. Correlation coefficients range between 0.4 and 0.47 , and statistical significance is always at least at the five percent level. The experimental profit measures also correlate positively with the overall performance rating in the company. Overall, the performance measures in the experimental task are highly correlated with the external evaluations of creativity, gestalt motivation, taking charge behavior and performance. This is evidence that behavior in management games like our ice cream task is an admissible proxy for innovative activity in companies. ${ }^{28}$

\section{Conclusion}

In this paper we argue that the connection between overconfidence and innovative activity is more nuanced than the existing literature suggests. We show theoretically and empirically that different forms of overconfidence can have opposing effects on exploratory behavior during the innovative process. While overoptimism is associated with an increase in exploration, which has been identified in previous field work, judgmental overconfidence is negatively associated with exploration. Our results indicate that future research is well advised to take into account that the relationship between innovation and overconfidence may crucially depend on the type of overconfidence that is most prevalent in a particular context.

Our paper makes a number of contributions. To the best of our knowledge we are the first pointing out that different forms of overconfidence can have opposing effects on innovative

\footnotetext{
${ }^{27}$ Remember that action orientation was also the only category in which the correlation between the HR and supervisor ratings was low. Probably our external measure of action orientation is very imprecise. In addition, by definition the concept of action orientation is more focused on the implementation of a given idea rather than the development of new ideas. Since the ice cream stand task is more closely related to the process of idea generation, it is plausible that action orientation is not an individual characteristic that is of particular importance in the experimental task.

${ }^{28} \mathrm{We}$ also regressed the score in every category separately on every single profit measure (regression results are available upon request), and cluster standard errors on supervisors (20 different supervisors are responsible for the 31 ratings). Significance of the regression coefficients is approximately in the same range as the pair-wise correlations reported here, which do not use clustered standard errors.
} 
activity. This is an important insight since overoptimism and judgmental overconfidence have not always been clearly distinguished in previous research. Moreover, our approach to experimentally study the individual determinants of innovative behavior is, again to the best of our knowledge, novel. Our experiments provide a behavioral measure that is a useful complement to the questionnaire and interview methods currently used for this kind of research. The external evidence provided in this paper suggests that experiments provide valid measurements of individual innovative activity.

Our results also contribute to the ongoing debate whether overconfidence is detrimental or favorable for social welfare. While both forms of overconfidence lead to inefficiencies on the individual level, increased innovation due to overoptimism may be socially desirable in case of positive externalities due to innovation that are not internalized. Contrarily, in situations in which there is an overprovision of innovative efforts, judgmental overconfidence can be socially beneficial.

Finally, we believe that the distinction between overoptimism and judgmental overconfidence provides interesting avenues for future research on the importance of overconfidence as a driver of innovation. From a theoretical perspective, distinguishing between overoptimism and judgmental overconfidence seems to be of importance in the screening process for innovators. If the cost of innovation is mainly borne by the employee, it might be beneficial to attract over-optimistic employees. This may be achieved through the provision of convex incentive schemes (Larkin and Leider, 2012). If innovative activity is suboptimally low in a society, convex incentive schemes like the patent system may be optimal to increase innovative activity through the additional selection effect caused by overoptimism. Judgmental overconfidence, on the other hand, may be harmful to the employer or society. In order to tackle the negative effects of judgmental overconfidence, firms should design more elaborate feedback mechanisms, as targeted feedback seems to be able to reduce decision-making biases (Eberlein et al., 2011). Future research is needed to shed further light on these questions. 


\section{References}

Alicke, Mark D., M. L. Klotz, David L. Breitenbacher, Tricia J. Yurak, and Debbie S. Vredenburg, "Personal Contact, Individuation, and the Better-Than-Average Effect," Journal of Personality and Social Psychology, 1995, 68 (5), pp. 804-825.

Arora, Ashish and Alfonso Gambardella, "The Market for Technology," in Bronwyn H. Hall and Nathan Rosenberg, eds., Handbook of The Economics of Innovation, Vol. 1, Vol. 1 of Handbook of the Economics of Innovation, North-Holland, 2010, pp. 641 - 678.

Bateman, Thomas S. and J. Michael Crant, "The Proactive Component of Organizational Behavior: A Measure and Correlates," Journal of Organizational Behavior, 1993, $14(2), 103-118$.

Benos, Alexandros V., "Aggressiveness and survival of overconfident traders," Journal of Financial Markets, September 1998, 1 (3-4), 353-383.

Bernardo, Antonio E. and Ivo Welch, "On the Evolution of Overconfidence and Entrepreneurs," Journal of Economics \&3 Management Strategy, 2001, 10 (3), 301-330.

Biais, Bruno, Denis Hilton, Karine Mazurier, and Sebastien Pouget, "Judgemental Overconfidence, Self-Monitoring, and Trading Performance in an Experimental Financial Market," The Review of Economic Studies, 2005, 72 (2), 287-312.

Blanchflower, David G. and Andrew J. Oswald, "What Makes an Entrepreneur?," Journal of Labor Economics, 1998, 16 (1), pp. 26-60.

Bolton, Patrick, Markus K Brunnermeier, and Laura Veldkamp, "Leadership, Coordination, and Corporate Culture," The Review of Economic Studies, 2013, 80 (2), 512537.

Camerer, Colin and Dan Lovallo, "Overconfidence and Excess Entry: An Experimental Approach," The American Economic Review, 1999, 89 (1), pp. 306-318.

Daniel, Kent, David Hirshleifer, and Avanidhar Subrahmanyam, "Investor Psychology and Security Market Under- and Overreactions," Journal of Finance, December 1998, 53 (6), 1839-1885.

Diamond, Peter A. and Joseph E. Stiglitz, "Increases in risk and in risk aversion," Journal of Economic Theory, July 1974, 8 (3), 337-360. 
Dubra, Juan, "Optimism and Overconfidence in Search," Review of Economic Dynamics, January 2004, 7 (1), 198-218.

Dunning, David, Judith A. Meyerowitz, and Amy D. Holzberg, "Ambiguity and Self-Evaluation: The Role of Idiosyncratic Trait Definitions in Self-Serving Assessments of Ability," Journal of Personality and Social Psychology, 1989, 57 (6), pp. 1082-1090.

Eberlein, Marion, Sandra Ludwig, and Julia Nafziger, "The Effects Of Feedback On Self-Assessment," Bulletin of Economic Research, 2011, 63 (2), 177-199.

Ederer, Florian and Gustavo Manso, "Is Pay For Performance Detrimental to Innovation," Management Science, July 2013, 59 (7), 1496-1513.

Evans, David S. and Linda S. Leighton, "Some Empirical Aspects of Entrepreneurship," The American Economic Review, 1989, 79 (3), pp. 519-535.

Fagerberg, Jan, Martin Srholec, and Bart Verspagen, "Innovation and Economic Development," in Bronwyn H. Hall and Nathan Rosenberg, eds., Handbook of the Economics of Innovation, Volume 2, Vol. 2 of Handbook of the Economics of Innovation, North-Holland, 2010, pp. $833-872$.

Fischbacher, Urs, "z-Tree: Zurich Toolbox for Ready-made Economic Experiments," Experimental Economics, 2007, 10 (2), 171-178.

Frese, Michael, Wolfgang Kring, Andrea Soose, and Jeannette Zempel, "Personal Initiative at Work: Differences between East and West Germany," The Academy of Management Journal, 1996, 39 (1), pp. 37-63.

Galasso, Alberto and Timothy S. Simcoe, "CEO Overconfidence and Innovation," Management Science, August 2011, 57 (8), 1469-1484.

Greiner, Ben, "The Online Recruitment System ORSEE - A Guide for the Organization of Experiments in Economics," Discussion Papers on Strategic Interaction 2003-10, Max Planck Institute of Economics, Strategic Interaction Group June 2004.

Grubb, Michael D., "Selling to Overconfident Consumers," The American Economic Review, December 2009, 99, 1770-1807(38).

Hall, Bronwyn H. and Josh Lerner, "The Financing of R\&D and Innovation," in Bronwyn H. Hall and Nathan Rosenberg, eds., Handbook of The Economics of Innovation, Vol. 1, Vol. 1 of Handbook of the Economics of Innovation, North-Holland, 2010, pp. 609 - 639. 
Heger, Stephanie A. and Nicholas W. Papageorge, "We Should Totally Open A Restaurant: A Taxonomy of Optimism and Overconfidence," Technical Report 2012.

Hilton, Denis, Isabelle Regner, Laure Cabantous, Laetitia Charalambides, and Stephane Vautier, "Do positive illusions predict overconfidence in judgment? A test using interval production and probability evaluation measures of miscalibration," Journal of Behavioral Decision Making, 2011, 24 (2), 117-139.

Hirshleifer, David, Angie Low, and Siew Hong Teoh, "Are Overconfident CEOs Better Innovators?," The Journal of Finance, August 2012, 67 (4), 1457-1498.

Hossiep, R. and M. Paschen, Bochumer Inventar zur berufsbezogenen Persönlichkeitsbeschreibung (BIP) (2. Aufl.), Hogrefe, 2003.

Hulten, Charles R., "Growth Accounting*," in Bronwyn H. Hall and Nathan Rosenberg, eds., Handbook of the Economics of Innovation, Volume 2, Vol. 2 of Handbook of the Economics of Innovation, North-Holland, 2010, pp. 987 - 1031.

Hurst, Erik and Annamaria Lusardi, "Liquidity Constraints, Household Wealth, and Entrepreneurship," Journal of Political Economy, 2004, 112 (2), pp. 319-347.

Jonsson, A.-C. and C.M. Allwood, "Stability and variability in the realism of confidence judgments over time, content domain, and gender," Personality and Individual Differences, March 2003, 34, 559-574(16).

Kihlstrom, R.E. and J.J. Laffont, "A general equilibrium entrepreneurial theory of firm formation based on risk aversion," The Journal of Political Economy, 1979, 87 (4), 719748.

Klayman, Joshua, Jack B. Soll, Claudia Gonzalez-Vallejo, and Sema Barlas, "Overconfidence: It Depends on How, What, and Whom You Ask," Organizational Behavior and Human Decision Processes, September 1999, 79 (3), 216-247.

Larkin, Ian and Stephen Leider, "Incentive Schemes, Sorting, and Behavioral Biases of Employees: Experimental Evidence," American Economic Journal: Microeconomics, 2012, 4 (2), 184-214.

Lichtenstein, Sarah, Baruch Fischhoff, and Lawrence D. Phillips, "Calibration of Probabilities: The State of the Art to 1980," in H. Jungermann and G. deZeew, eds., Decision Making and the Change in Human Affairs, D. Rede, 1982, pp. 602-642. 
Lowe, Robert A. and Arvids A. Ziedonis, "Overoptimism and the Performance of Entrepreneurial Firms," Management Science, February 2006, 52 (2), 173-186.

March, James G., "Exploration and Exploitation in Organizational Learning," Organization Science, 1991, 2 (1), 71-87.

Moore, Don A. and Paul J. Healy, "The trouble with overconfidence," Psychological Review, 2008, 115.

Morrison, Elizabeth Wolfe and Corey C. Phelps, "Taking Charge at Work: Extrarole Efforts to Initiate Workplace Change," The Academy of Management Journal, 1999, 42 (4), 403-419.

Odean, Terrance, "Volume, Volatility, Price, and Profit When All Traders Are above Average," Journal of Finance, 1998, 53 (6), pp. 1887-1934.

Parker, A. and B. Fischhoff, "Decision-Making Competence: An Individual Differences Approach," Journal of Behavioral Decision Making, January 2005, 18, 1-27.

Parker, Sharon K., "Enhancing Role Breadth Self-Efficacy: The Roles of Job Enrichment and Other Organizational Interventions," Journal of Applied Psychology, 1998, 83 (6), 835 -852 .

Raven, J., J.C. Raven, and J.H. Court, Manual for Raven's Progressive Matrices and Vocabulary Scales, Harcourt Assessment, 2003.

Russo, J. and P.J.H. Schoemaker, "Managing Over-Confidence," Sloan Management Review, 1992, 33, 7-17.

Spinnewijn, Johannes, "Unemployed but Optimistic: Optimal Insurance Design with Biased Beliefs," Technical Report 2010.

Svenson, Ola, "Are we all less risky and more skillful than our fellow drivers?," Acta Psychologica, 1981, 47 (2), $143-148$.

Unsworth, Kerrie, "Unpacking Creativity," The Academy of Management Review, 2001, 26 (2), pp. 289-297.

Unsworth, Kerrie L. and Sharon Parker, "Proactivity and Innovation: Promoting a New Workforce for the New Workplace," in David Holman, Toby D. Wall, Chris W. Clegg, Paul Sparrow, and Ann Howard, eds., The new Workplace: A Guide to Human Impact of Modern Working Practices, John Wiley \& Sons, 2003, pp. 175-196. 


\section{Appendix A: Proofs}

In this section, we formally prove the Lemma and Propositions 1 and 2 from section 3.

\section{Proof of the Lemma (Optimal Stopping Rule)}

We first focus on the agent's optimal stopping rule in the compensation phase $(t>\bar{t})$, when immediate payments occur. Second, we extend the analysis and determine the optimal stopping rule in the non-compensation phase $(t \leq \bar{t})$.

\section{Optimal stopping rule in the compensation phase $(t>\bar{t})$}

To derive the optimal stopping threshold of an agent in periods $t>\bar{t}$, we first show that if an agent's optimal choice is to explore in period $t$, then the agent's optimal choice in period $t-1$ is also to explore. This implies that an optimally behaving agent who chooses to exploit in period $t<T$, will never switch to explore in any later period $t^{\prime}>t$.

The proof is by contradiction. Define $V_{t}\left(\omega^{m}\right)$ as the continuation value of having a best idea $\omega_{t}^{m}=\omega^{m}$ at the beginning of period $t$ if the agent chooses optimally between exploitation and exploration in every period $t^{\prime} \geq t$. Assume that an agent who has access to a best idea $\omega^{m} \geq \mu$ prefers to explore in period $t .^{29}$ This implies:

$$
\begin{array}{r}
\mu+\delta F\left(\omega^{m}\right) V_{t+1}\left(\omega^{m}\right)+\delta \int_{\omega^{m}}^{\infty} f(\omega) V_{t+1}(\omega) d \omega \geq \omega^{m}+\delta V_{t+1}\left(\omega^{m}+\epsilon\right), \text { or } \\
\delta F\left(\omega^{m}\right) V_{t+1}\left(\omega^{m}\right)+\delta \int_{\omega^{m}}^{\infty} f(\omega) V_{t+1}(\omega) d \omega-\delta V_{t+1}\left(\omega^{m}+\epsilon\right) \geq \omega^{m}-\mu .
\end{array}
$$

The best idea available to the agent in period $t-1$ must satisfy $\omega_{t-1}^{m} \leq \omega^{m}$. If $\omega_{t-1}^{m}=\omega^{m}$, the agent exploits if:

$$
\delta F\left(\omega^{m}\right) V_{t}\left(\omega^{m}\right)+\delta \int_{\omega^{m}}^{\infty} f(\omega) V_{t}(\omega) d \omega-\delta V_{t}\left(\omega^{m}+\epsilon\right) \leq \omega^{m}-\mu .
$$

Switching from exploitation in period $t-1$ to exploration in period $t$, requires that conditions (1) and (2) are satisfied at the same time. This implies:

$$
\begin{gathered}
F\left(\omega^{m}\right) V_{t}\left(\omega^{m}\right)+\int_{\omega^{m}}^{\infty} f(\omega) V_{t}(\omega) d \omega-V_{t}\left(\omega^{m}+\epsilon\right) \leq \\
F\left(\omega^{m}\right) V_{t+1}\left(\omega^{m}\right)+\int_{\omega^{m}}^{\infty} f(\omega) V_{t+1}(\omega) d \omega-V_{t+1}\left(\omega^{m}+\epsilon\right) .
\end{gathered}
$$

\footnotetext{
${ }^{29}$ Our assumption that $\epsilon \leq \int_{\mu}^{\infty} f(\omega)(\omega-\mu) d \omega$ implies that exploitation is never optimal if $\omega^{m}<\mu$.
} 
The first thing to note is that, obviously, the continuation value $V_{t}(\omega)$ is weakly increasing in $\omega, \frac{\partial V_{t}\left(\omega_{t}^{m}\right)}{\partial \omega_{t}^{m}} \geq 0$. With a better idea at hand, the agent can always mimic the optimal strategy given a worse idea, which in expectation yields a higher payoff in those periods in which the agent exploits. Second, the continuation value $V_{t}(\omega)$ is decreasing in $t, \frac{\partial V_{t}\left(\omega_{t}^{m}\right)}{\partial t}<0$. The payoff in every period is, in expectation, positive. Reducing the number of periods must therefore reduce the continuation value, given $\omega^{m}$. Third, an agent with a better idea can in expectation always do at least as good as an agent with a worse idea in any future period, and therefore the increase in continuation value in $\omega$ can not be decreasing as the remaining time horizon gets longer. In other words, the marginal increase in value from a marginally better idea is larger the longer the remaining time horizon. This implies $\frac{\partial^{2} V_{t}\left(\omega_{t}^{m}\right)}{\partial \omega_{t}^{m} \partial t} \leq 0$.

These conditions imply that $V_{t}(\omega)$ is a convex transformation of $V_{t+1}(\omega)$. Let's denote this transformation by $g_{t+1}\left(V_{t+1}(\omega)\right)=V_{t}(\omega)$. We can then rewrite equation (3) as follows:

$$
\begin{gathered}
F\left(\omega^{m}\right) V_{t+1}\left(\omega^{m}\right)+\int_{\omega^{m}}^{\infty} f(\omega) V_{t+1}(\omega) d \omega-\left[F\left(\omega^{m}\right) g_{t+1}\left(V_{t+1}\left(\omega^{m}\right)\right)+\int_{\omega^{m}}^{\infty} f(\omega) g_{t+1}\left(V_{t+1}(\omega)\right) d \omega\right] \geq \\
V_{t+1}\left(\omega^{m}+\epsilon\right)-g_{t+1}\left(V_{t+1}\left(\omega^{m}+\epsilon\right)\right) .
\end{gathered}
$$

Because $g_{t+1}$ is a convex transformation, Jensen's inequality implies that

$$
\begin{gathered}
g_{t+1}\left[F\left(\omega^{m}\right) V_{t+1}\left(\omega^{m}\right)+\int_{\omega^{m}}^{\infty} f(\omega) V_{t+1}(\omega) d \omega\right] \leq \\
F\left(\omega^{m}\right) g_{t+1}\left(V_{t+1}\left(\omega^{m}\right)\right)+\int_{\omega^{m}}^{\infty} f(\omega) g_{t+1}\left(V_{t+1}(\omega)\right) d \omega
\end{gathered}
$$

This in turn implies that

$$
\begin{array}{r}
F\left(\omega^{m}\right) V_{t+1}\left(\omega^{m}\right)+\int_{\omega^{m}}^{\infty} f(\omega) V_{t+1}(\omega) d \omega-\left[F\left(\omega^{m}\right) g_{t+1}\left(V_{t+1}\left(\omega^{m}\right)\right)+\int_{\omega^{m}}^{\infty} f(\omega) g_{t+1}\left(V_{t+1}(\omega)\right) d \omega\right] \leq \\
F\left(\omega^{m}\right) V_{t+1}\left(\omega^{m}\right)+\int_{\omega^{m}}^{\infty} f(\omega) V_{t+1}(\omega) d \omega-g_{t+1}\left[F\left(\omega^{m}\right) V_{t+1}\left(\omega^{m}\right)+\int_{\omega^{m}}^{\infty} f(\omega) V_{t+1}(\omega) d \omega\right] .
\end{array}
$$

In addition, note that

$$
\begin{array}{r}
F\left(\omega^{m}\right) V_{t+1}\left(\omega^{m}\right)+\int_{\omega^{m}}^{\infty} f(\omega) V_{t+1}(\omega) d \omega-g_{t+1}\left[F\left(\omega^{m}\right) V_{t+1}\left(\omega^{m}\right)+\int_{\omega^{m}}^{\infty} f(\omega) V_{t+1}(\omega) d \omega\right] \leq \\
V_{t+1}\left(\omega^{m}+\epsilon\right)-g_{t+1}\left(V_{t+1}\left(\omega^{m}+\epsilon\right)\right) .
\end{array}
$$

Equation (7) follows because $F\left(\omega^{m}\right) V_{t+1}\left(\omega^{m}\right)+\int_{\omega^{m}}^{\infty} f(\omega) V_{t+1}(\omega) d \omega>V_{t+1}\left(\omega^{m}+\epsilon\right)$, which 
is implied by the optimality of exploration in $t+1$, and because of the convexity of $g_{t+1}$.

But equations (7) and (6) together imply that

$$
\begin{gathered}
F\left(\omega^{m}\right) V_{t+1}\left(\omega^{m}\right)+\int_{\omega^{m}}^{\infty} f(\omega) V_{t+1}(\omega) d \omega-\left[F\left(\omega^{m}\right) g_{t+1}\left(V_{t+1}\left(\omega^{m}\right)\right)+\int_{\omega^{m}}^{\infty} f(\omega) g_{t+1}\left(V_{t+1}(\omega)\right) d \omega\right] \leq \\
V_{t+1}\left(\omega^{m}+\epsilon\right)-g_{t+1}\left(V_{t+1}\left(\omega^{m}+\epsilon\right)\right),
\end{gathered}
$$

which contradicts equation (4), and therefore also equation (3). Intuitively, as $t$ increases there are fewer periods to exploit the benefits of having an idea better than $\bar{\omega}+\epsilon$, and hence the potential future benefits of exploration become smaller the larger $t$. This implies that it can never be optimal to switch from exploitation back to exploration.

The fact that it is never optimal for an agent to switch back to exploring once she has started to exploit implies that there exists a period-dependent stopping threshold. Let's denote $\bar{\omega}_{t}$ as the agent's stopping threshold in period $t$. If the best idea available in period $t$ exceeds the threshold, the agent exploits, otherwise he explores. Since an agent will never switch from exploitation back to exploration, the stopping threshold must be weakly decreasing over time: $\frac{\partial V_{t}\left(\bar{\omega}_{t}\right)}{\partial t} \leq 0$.

Assume that the best idea available to the agent in period $t$ is $\omega_{t}^{m}$. If it turns out that exploitation is optimal in period $t$ (and all following periods $t^{\prime}>t$ ), the agent's present value is:

$$
\begin{aligned}
V_{t}\left(\omega_{t}^{m}\right) & =\sum_{\tau=0}^{T-t} \delta^{\tau}\left(\omega_{t}^{m}+(\tau) \epsilon\right) \\
V_{t}\left(\omega_{t}^{m}\right) & =\frac{1-\delta^{T-t+1}}{1-\delta} \omega_{t}^{m}+\sum_{\tau=0}^{T-t} \delta^{\tau}(\tau) \epsilon
\end{aligned}
$$

If the agent decides to explore in period $t$ instead, the present value depends not only on the explore-exploit decision in period $t$, but also on the explore-exploit decision in all subsequent periods. To determine the stopping threshold in period $t$, however, it suffices to analyze the value of the exploration strategy under the assumption that the best idea available to the agent in period $t$ already exceeds the stopping threshold in period $t+1$ : $\omega_{t}^{m}>\bar{\omega}_{t+1}$. If it is optimal to explore in period $t$ if $\omega_{t}^{m}>\bar{\omega}_{t+1}$, this will necessarily also be the case for smaller values of $\omega_{t}^{m}$, since the value of exploitation is then strictly smaller. The agent's present value if he explores in period $t$ is therefore given by 


$$
\begin{aligned}
& V_{t}\left(\omega_{t}^{m}\right)=\mu+F\left(\omega_{t}^{m}\right) \sum_{\tau=1}^{T-t} \delta^{\tau}\left(\omega_{t}^{m}+\tau \epsilon\right)+\int_{\omega^{m}}^{\infty} \sum_{\tau=1}^{T-t} \delta^{\tau}(\omega+\tau \epsilon) d \omega \\
& V_{t}\left(\omega_{t}^{m}\right)=\mu+F\left(\omega_{t}^{m}\right) \frac{\delta-\delta^{T-t+1}}{1-\delta} \omega_{t}^{m}+\frac{\delta-\delta^{T-t+1}}{1-\delta} \int_{\omega^{m}}^{\infty} f(\omega) \omega d \omega+\sum_{\tau=1}^{T-t} \delta^{\tau}(\tau-1) \epsilon
\end{aligned}
$$

The stopping threshold $\bar{\omega}_{t}$ is therefore defined as the $\omega_{t}^{m}$ which equalizes the right-hand sides of equations (9) and (10). Implicitly, the stopping threshold $\bar{\omega}_{t}$ is defined by the following condition:

$$
\left[1-\delta^{T-t+1}-\left(\delta-\delta^{T-t+1}\right) F\left(\bar{\omega}_{t}\right)\right] \bar{\omega}_{t}-\left(\delta-\delta^{T-t+1}\right) \int_{\bar{\omega}_{t}}^{\infty} f(\omega) \omega d \omega=(1-\delta) \mu-\left(\delta-\delta^{T-t}\right) \epsilon .(11)
$$

The derivative of the left-hand side of equation (11) with respect to $\bar{\omega}_{t}$ is strictly positive:

$$
1-\delta^{T-t+1}-\left(\delta-\delta^{T-t+1}\right) F\left(\bar{\omega}_{t}\right)>0 .
$$

This implies that the stopping threshold $\bar{\omega}_{t}$ is unique.

\section{Optimal stopping rule in the non-compensation phase $(t \leq \bar{t})$}

In the previous section, we have established that the stopping threshold is strictly decreasing if $t>\bar{t}$. Moreover, it is obvious that in period $T$, the stopping threshold must be given by $\bar{\omega}_{T}=\mu$. Consequently, we have established that $\bar{\omega}_{\bar{t}+1}>\bar{\omega}_{\bar{t}+2}>\cdots>\bar{\omega}_{T}=\mu$.

We know that the threshold in period $\bar{t}+1$ satisfies the following equation:

$$
\delta F\left(\bar{\omega}_{\bar{t}+1}\right) V_{\bar{t}+2}\left(\bar{\omega}_{\bar{t}+1}\right)+\delta \int_{\bar{\omega}_{\bar{t}+1}}^{\infty} f(\omega) V_{\bar{t}+2}(\omega) d \omega-\delta V_{\bar{t}+2}\left(\bar{\omega}_{\bar{t}+1}+\epsilon\right)=\bar{\omega}_{\bar{t}+1}-\mu .
$$

Now, assume that $\omega_{\bar{t}}^{m}=\bar{\omega}_{\bar{t}+1}$. Will the agent explore or exploit? Since there are no more immediate payments in the non-compensation phase, the agent exploits if:

$$
\delta F\left(\bar{\omega}_{\bar{t}+1}\right) V_{\bar{t}+1}\left(\bar{\omega}_{\bar{t}+1}\right)+\delta \int_{\bar{\omega}_{\bar{t}+1}}^{\infty} f(\omega) V_{\bar{t}+1}(\omega) d \omega-\delta V_{\bar{t}+1}\left(\bar{\omega}_{\bar{t}+1}+\epsilon\right)<0 .
$$

But we know that $\bar{\omega}_{\bar{t}+1}>\mu$. Hence, exploration became strictly cheaper in period $\bar{t}$ compared to period $\bar{t}+1$. Moreover, since $\omega_{t+1}^{m} \geq \bar{\omega}_{\bar{t}+1}$, there will only be exploitation in 
periods $t>\bar{t}$. This implies that, for $\omega \geq \bar{\omega}_{\bar{t}+1}$, we have:

$$
V(\omega, t)=\sum_{\tau=0}^{T-t} \delta^{\tau}(\omega+\tau \epsilon)
$$

But this continuation value function again implies that $\frac{\partial^{2} V_{t}\left(\omega_{t}^{m}\right)}{\partial \omega_{t}^{m} \partial t} \leq 0$, which, as before, implies that

$$
\begin{gathered}
F\left(\bar{\omega}_{\bar{t}+1}\right) V_{\bar{t}+1}\left(\bar{\omega}_{\bar{t}+1}\right)+\int_{\bar{\omega}_{\bar{t}+1}}^{\infty} f(\omega) V_{\bar{t}+1}(\omega) d \omega-V_{\bar{t}+1}\left(\bar{\omega}_{\bar{t}+1}+\epsilon\right)> \\
F\left(\bar{\omega}_{\bar{t}+1}\right) V_{\bar{t}+2}\left(\bar{\omega}_{\bar{t}+1}\right)+\int_{\bar{\omega}_{\bar{t}+1}}^{\infty} f(\omega) V_{\bar{t}+2}(\omega) d \omega-V_{\bar{t}+2}\left(\bar{\omega}_{\bar{t}+2}+\epsilon\right)
\end{gathered}
$$

and therefore the following inequality holds:

$$
\delta V_{\bar{t}+1}\left(\bar{\omega}_{\bar{t}+1}+\epsilon\right)<\delta F\left(\bar{\omega}_{\bar{t}+1}\right) V_{\bar{t}+1}\left(\bar{\omega}_{\bar{t}+1}\right)+\delta \int_{\bar{\omega}_{\bar{t}+1}}^{\infty} f(\omega) V_{\bar{t}+1}(\omega) d \omega
$$

Consequently, equation 13 can never be fulfilled and we must have $\bar{\omega}_{\bar{t}}>\bar{\omega}_{\bar{t}+1}$

This result is of course very intuitive. Since $\bar{\omega}_{\bar{t}+1}>\mu$, exploration has lower opportunity costs in period $\bar{t}$ then in period $\bar{t}+1$. At the same time, the continuation value of exploration is relatively larger in period $\bar{t}$ because the benefits of better ideas can be exploited in one additional period. Both effects favour exploration.

But what happens in periods 1-9? We know that the agent will exploit all ideas $\omega \geq \bar{\omega}_{\bar{t}}$ in every period from period $\bar{t}+1$ onwards. The continuation value for such ideas is therefore linear. Consider the situation in which $\omega_{\bar{t}-1}^{m}=\bar{\omega}_{\bar{t}}$. The agent will exploit if

$$
V_{\bar{t}}\left(\bar{\omega}_{\bar{t}}+\epsilon\right)>F\left(\bar{\omega}_{\bar{t}}\right) V_{\bar{t}}\left(\bar{\omega}_{\bar{t}}\right)+\int_{\bar{\omega}_{\bar{t}}}^{\infty} f(\omega) V_{\bar{t}}(\omega) d \omega
$$

Because the best available idea in period $\bar{t}$ is then at least $\bar{\omega}_{\bar{t}}$, the agent exploits for sure in period $\bar{t}$. This implies for equation (17):

$$
V_{\bar{t}+1}\left(\bar{\omega}_{\bar{t}}+2 \epsilon\right)>F\left(\bar{\omega}_{\bar{t}}\right) V_{\bar{t}+1}\left(\bar{\omega}_{\bar{t}}+\epsilon\right)+\int_{\bar{\omega}_{\bar{t}}}^{\infty} f(\omega) V_{\bar{t}+1}(\omega+\epsilon) d \omega
$$

which, because of the linearity of $V_{\bar{t}+1}(\omega)$, is equivalent to 


$$
V_{\bar{t}+1}\left(\bar{\omega}_{\bar{t}}+\epsilon\right)>F\left(\bar{\omega}_{\bar{t}}\right) V_{\bar{t}+1}\left(\bar{\omega}_{\bar{t}}\right)+\int_{\bar{\omega}_{\bar{t}}}^{\infty} f(\omega) V_{\bar{t}+1}(\omega) d \omega
$$

But this is precisely the identity that defined $\bar{\omega}_{\bar{t}}$. Consequently, it must be that $\bar{\omega}_{\bar{t}-1}=\bar{\omega}_{\bar{t}}$, and the same logic holds for every threshold value prior to period $\bar{t}-1$. Therefore, the stopping threshold in periods $t \leq \bar{t}$ is implicitly defined by the following equation: ${ }^{30}$

$$
\left[\delta-\delta^{\bar{t}+1}-\left(\delta-\delta^{\bar{t}+1}\right) F\left(\bar{\omega}_{\bar{t}}\right)\right] \bar{\omega}_{\bar{t}}-\left(\delta-\delta^{\bar{t}+1}\right) \int_{\bar{\omega}_{t}}^{\infty} f(\omega) \omega d \omega=-\left(1-\delta^{\bar{t}+1}\right) \epsilon .
$$

Again, the derivative of the left-hand side of equation (18) with respect to $\bar{\omega}_{t}$ is strictly positive:

$$
\delta-\delta^{T-t+1}-\left(\delta-\delta^{T-t+1}\right) F\left(\bar{\omega}_{t}\right)>0
$$

which implies that the stopping threshold $\bar{\omega}_{t}$ in periods $t \leq \bar{t}$ is also unique.

The logic behind this result is again very intuitive. Because the continuation value function $V_{\bar{t}+1}(\omega)$ is linear in $\omega$ for $\omega \geq \bar{\omega}_{\bar{t}}$, the stopping problem in periods prior to period $\bar{t}$ boils down to maximizing the expected continuation value of $\omega$. Hence in every period, the action is taken that incrementally increases the expected continuation value the most, and there is exactly one value for $\omega$ at which the constant increase $\epsilon$ exactly equals the expected value increase from exploration. This is the case because the added benefit from exploration is strictly decreasing in $\omega$, whereas the increase in value from adding $\epsilon$ is constant, given that the continuation value function is linear in $\omega$ in the relevant domain.

\footnotetext{
${ }^{30}$ Equation (18) follows from equating the continuation value in period $\bar{t}+1$ of the exploitation and the exploration strategy, which, for exploitation, is given by

$$
\frac{\delta-\delta^{\bar{t}+1}}{1-\delta} \omega_{\bar{t}}^{m}+\sum_{\tau=1}^{\bar{t}} \delta^{\tau}(\tau) \epsilon
$$
}

and for exploration is given by

$$
F\left(\omega_{\bar{t}}^{m}\right) \frac{\delta-\delta^{\bar{t}+1}}{1-\delta} \omega_{\bar{t}}^{m}+\frac{\delta-\delta^{\bar{t}+1}}{1-\delta} \int_{\omega_{\bar{t}}^{m}}^{\infty} f(\omega) \omega d \omega+\sum_{\tau=1}^{\bar{t}} \delta^{\tau} \tau \epsilon .
$$




\section{Proof of Proposition 1: The Effect of Judgmental Overconfidence}

We investigate how the agent's distorted belief about the variance in the distribution of business strategies $\left(\hat{\sigma}_{i}<\sigma_{i}\right)$ affects the thresholds $\bar{\omega}_{t}$. For this purpose we consider two distributional functions: $F_{1}(\omega)=F\left(\omega, \mu, \sigma_{1}\right)$ and $F_{2}(\omega)=F\left(\omega, \mu, \sigma_{2}\right)$. We follow Diamond and Stiglitz (1974) and assume that $F_{2}(\omega)$ results from a mean preserving spread of $F_{1}(\omega)$ so that the two distribution functions cross exactly once (at $\hat{\omega})$ :

$$
F_{2}(\omega)-F_{1}(\omega) \leq(\geq) 0 \text { when } \omega \geq(\leq) \hat{\omega}
$$

We show that the stopping threshold $\bar{\omega}_{t}$ of an agent who believes that the idea distribution function is given by $F_{1}(\omega)$ is strictly smaller than the threshold of an agent who believes that the idea distribution function is given by $F_{2}(\omega)$ (see equation (11) for the definition of $\left.\bar{\omega}_{t}\right)$ :

$$
\begin{aligned}
& {\left[1-\delta^{T-t+1}-\left(\delta-\delta^{T-t+1}\right) F_{1}(\bar{\omega})\right] \bar{\omega}-\left(\delta-\delta^{T-t+1}\right) \int_{\bar{\omega}}^{\infty} f_{1}(\omega) \omega d \omega \geq} \\
& {\left[1-\delta^{T-t+1}-\left(\delta-\delta^{T-t+1}\right) F_{2}(\bar{\omega})\right] \bar{\omega}-\left(\delta-\delta^{T-t+1}\right) \int_{\bar{\omega}}^{\infty} f_{2}(\omega) \omega d \omega .}
\end{aligned}
$$

This can be rewritten as ${ }^{31}$

$$
\begin{aligned}
F_{2}(\bar{\omega}) \bar{\omega}+\int_{\bar{\omega}}^{\infty} f_{2}(\omega) \omega d \omega & \geq F_{1}(\bar{\omega}) \bar{\omega}+\int_{\bar{\omega}}^{\infty} f_{1}(\omega) \omega d \omega \\
\int_{\bar{\omega}}^{\infty} f_{2}(\omega) \omega d \omega-\int_{\bar{\omega}}^{\infty} f_{1}(\omega) \omega d \omega & \geq F_{1}(\bar{\omega}) \bar{\omega}-F_{2}(\bar{\omega}) \bar{\omega} \\
\int_{\bar{\omega}}^{\infty}\left[f_{2}(\omega)-f_{1}(\omega)\right] \omega d \omega & \geq\left(F_{1}(\bar{\omega})-F_{2}(\bar{\omega})\right) \bar{\omega}
\end{aligned}
$$

Note that

$$
F_{1}(\bar{\omega})-F_{2}(\bar{\omega})=\int_{-\infty}^{\bar{\omega}}\left[f_{1}(\omega)-f_{2}(\omega)\right] d \omega=\int_{\bar{\omega}}^{\infty}\left[f_{2}(\omega)-f_{1}(\omega)\right] d \omega
$$

Therefore, we can further rewrite as follows:

$$
\begin{aligned}
\int_{\bar{\omega}}^{\infty}\left[f_{2}(\omega)-f_{1}(\omega)\right] \omega d \omega & \geq \int_{\bar{\omega}}^{\infty}\left[f_{2}(\omega)-f_{1}(\omega)\right] \bar{\omega} d \omega \\
\int_{\bar{\omega}}^{\infty}\left[f_{2}(\omega)-f_{1}(\omega)\right](\omega-\bar{\omega}) d \omega & \geq 0 .
\end{aligned}
$$

\footnotetext{
${ }^{31}$ Note that equation (20) also immediately follows from a similar comparison of equation (18). Hence, the proof applies to stopping thresholds in all periods.
} 
Equation (22) is satisfied as a direct consequence of condition (19). This can be seen as follows: If $\bar{\omega} \geq \hat{\omega}$, condition (22) follows immediately by stochastic dominance of $F_{2}$ over $F_{1}$ in the relevant domain. If $\bar{\omega}<\hat{\omega}$, condition (22) follows from the fact that (22) holds with equality for $\bar{\omega} \rightarrow-\infty$ and (22) is strictly positive for some $\bar{\omega} \geq \hat{\omega}$. By condition (19), equation (22) must then also hold for all $\bar{\omega}>-\infty$.

This implies that a decrease in the variance unambiguously leads to a decrease in the threshold. Hence, judgmental overconfidence reduces exploration incentives.

\section{Proof of Proposition 2: The Effect of Overoptimism}

We investigate how the agent's distorted belief about the mean of the distribution of business strategies $\left(\hat{\mu}_{i}>\mu_{i}\right)$ affects the thresholds $\bar{\omega}_{t}$. For this purpose we compare two otherwise identical distributions with different means: $F_{1}(\omega)=F\left(\omega, \mu_{1}, \sigma\right)$ and $F_{2}(\omega)=F\left(\omega, \mu_{2}, \sigma\right)$, where $\mu_{1}>\mu_{2} . F_{2}(\omega)$ results from a translation of the density function of $F_{1}(\omega)$ to the right. This keeps all moments of the distribution other than the mean constant. The translation to the right implies first-order stochastic dominance, i. e., $F_{1}(\omega) \leq F_{2}(\omega) \forall \omega$.

We show that the stopping threshold $\bar{\omega}_{t}$ of an agent who believes that the idea distribution function is given by $F_{1}(\omega)$ is strictly larger than the threshold of an agent who believes that the idea distribution function is given by $F_{2}(\omega)$ (see equation (11) for the definition of $\bar{\omega}_{t}$ ):

$$
\begin{aligned}
& {\left[1-\delta^{T-t+1}-\left(\delta-\delta^{T-t+1}\right) F_{1}(\bar{\omega})\right] \bar{\omega}-\left(\delta-\delta^{T-t+1}\right) \int_{\bar{\omega}}^{\infty} f_{1}(\omega) \omega d \omega-(1-\delta) \mu_{1} \leq} \\
& {\left[1-\delta^{T-t+1}-\left(\delta-\delta^{T-t+1}\right) F_{2}(\bar{\omega})\right] \bar{\omega}-\left(\delta-\delta^{T-t+1}\right) \int_{\bar{\omega}}^{\infty} f_{2}(\omega) \omega d \omega-(1-\delta) \mu_{2} .}
\end{aligned}
$$

This can be rewritten as ${ }^{32}$

$$
\left[F_{1}(\bar{\omega})-F_{2}(\bar{\omega})\right] \bar{\omega}+\int_{\bar{\omega}}^{\infty}\left[f_{1}(\omega)-f_{2}(\omega)\right] \omega d \omega+\frac{1-\delta}{\delta-\delta^{T-t+1}}\left(\mu_{1}-\mu_{2}\right) \geq 0
$$

Using again equation (21) we can further rewrite:

$$
\int_{\bar{\omega}}^{\infty}\left[f_{1}(\omega)-f_{2}(\omega)\right](\omega-\bar{\omega}) d \omega+\frac{1-\delta}{\delta-\delta^{T-t+1}}\left(\mu_{1}-\mu_{2}\right) \geq 0
$$

This inequality follows immediately from first order stochastic dominance. It follows that an increase in $\mu_{i}$ leads to an increase in $\bar{\omega}$. Overoptimism therefore unambiguously leads to an increase in exploratory behavior.

\footnotetext{
${ }^{32}$ Note again that the proof looks similar for the stopping threshold in periods $t \leq \bar{t}$. The only difference is that the term $\frac{1-\delta}{\delta-\delta^{T-t+1}}\left(\mu_{1}-\mu_{2}\right)$ drops out, which does not affect the proof.
} 


\section{Appendix B: Additional Tables}

Table B.1: Summary Statistics of Supervisor Ratings

\begin{tabular}{lccccc}
\hline \hline Variable & Mean & Std. Dev. & Min. & Max. & Obs. \\
\hline Creativity & 0.651 & 0.229 & 0 & 1 & 32 \\
Gestalt Motivation & 0.749 & 0.16 & 0.375 & 1 & 32 \\
Action Orientation & 0.664 & 0.173 & 0.241 & 0.944 & 32 \\
Taking Charge & 0.709 & 0.153 & 0.325 & 1 & 32 \\
Performance & 0.694 & 0.207 & 0.292 & 1 & 32 \\
\hline \hline
\end{tabular}

Summary statistics of a transformed measure that reflects the realized percentage of achievable points in the reported measure.

Table B.2: External Data Questionnaires

\begin{tabular}{lll}
\hline \hline Questionnaire & Source & Correlation $^{1}$ \\
\hline Taking charge & Morrison and Phelps (1999) & $0.66^{* * *}$ \\
Action orientation & Hossiep and Paschen (2003) & 0.32 \\
Gestalt motivation & Hossiep and Paschen (2003) & $0.62^{* * *}$ \\
Creativity & own items & $0.46^{* *}$ \\
Performance & own items & $0.64^{* * *}$ \\
\hline \hline
\end{tabular}

${ }^{1}$ Correlation reports the pair-wise correlation coefficient between the supervisor and the HR rating. Significance levels: ${ }^{*} \mathrm{p}<0.1,{ }^{* *} \mathrm{p}<0.05,{ }^{* * *}$ $\mathrm{p}<0.01$.

Table B.3: External Data Questionnaires

\begin{tabular}{lcccrc}
\hline \hline & $\begin{array}{c}(1) \\
\text { Creativity }\end{array}$ & $\begin{array}{c}(2) \\
\text { Gestalt } \\
\text { motivation }\end{array}$ & $\begin{array}{c}(3) \\
\text { Action } \\
\text { orientation }\end{array}$ & $\begin{array}{c}(4) \\
\text { Taking } \\
\text { Charge }\end{array}$ & $\begin{array}{c}(5) \\
\text { Per- } \\
\text { formance }\end{array}$ \\
\hline Profit Period & 0.26 & $0.32^{*}$ & 0.08 & 0.27 & $0.41^{* *}$ \\
11-20 (Points) & $(0.12)$ & $(0.07)$ & $(0.68)$ & $(0.012)$ & $(0.02)$ \\
Max. Period & 0.20 & 0.28 & 0.11 & 0.23 & $0.39^{* *}$ \\
Profit (Points) & $(0.26)$ & $(0.12)$ & $(0.54)$ & $(0.19)$ & $(0.03)$ \\
Observations & 26 & 26 & 26 & 26 & 26 \\
\hline \hline
\end{tabular}

Pairwise correlation coefficients between experimental measures and external survey measures (pooled ratings from supervisors and the HR department). P-values are reported in parentheses. Significance levels: ${ }^{*} \mathrm{p}<0.1,{ }^{* *} \mathrm{p}<0.05,{ }^{* * *} \mathrm{p}<0.01$. 


\section{Appendix C: Parameters used in the Ice Cream Stand Task}

Table C.1: Optimal product mix and maximal achievable profit by location

\begin{tabular}{lccc}
\hline \hline & Business District & School & Stadium \\
\hline Sugar Content & $1.5 \%$ & $9.5 \%$ & $5.5 \%$ \\
Flavor Intensity & $7.5 \%$ & $1.5 \%$ & $5.5 \%$ \\
Color & light & bright & light \\
Price & 7.5 & 2.5 & 7.5 \\
Maximum Profit (excluding flavor) & 100 & 200 & 60 \\
\hline \hline
\end{tabular}

Table C.2: Penalty factors for deviation from the optimal product mix

\begin{tabular}{lccc}
\hline \hline & Business District & School & Stadium \\
\hline Sugar Content & 5 & 6 & 0.5 \\
Flavor Intensity & 5 & 6 & 0.5 \\
Color & 20 & 60 & 0.5 \\
Price & 5 & 6 & 0.5 \\
\hline \hline
\end{tabular}

Table C.3: The effect of flavor on profit

\begin{tabular}{lc}
\hline \hline Flavor & Factor \\
\hline Lemon & 3.15 \\
Joghurt & 2.6 \\
Nut & 1.9 \\
Banana & 1.45 \\
Walnut & 1.4 \\
Cherry & 1.2 \\
Orange & 1.15 \\
Woodruff & 1.08 \\
Raspberry & 1.0 \\
56 other flavors & $0.9-1.0$ \\
\hline \hline
\end{tabular}




\section{Appendix D: Questionnaires}

\section{Judgmental Overconfidence Questionnaire}

Miscalibration Questions (True Answers in parantheses) ${ }^{33}$

1. Martin Luther King's age at death (39).

2. Length (in kilometers) of the Nile River (6671).

3. Number of countries that are members of OPEC (12).

4. Number of books in the Old Testament (5).

5. Weight (in kgs) of an empty Boeing 747 (180890).

6. Year in which J.S. Bach was born (1685).

7. Gestation period (in days) of an Asian elephant (645).

8. Diameter (in kilometers) of the moon (3475).

9. Air distance (in kilometers) from London to Tokyo (9550).

10. Deepest known point (in meters) in the oceans (11034).

\section{External Questionnaires Given to the Supervisors and the HR}

Taking Charge Questionnaire (5-point Likert Scale) $)^{34}$

This person often...

1. tries to adopt improved procedures for doing his or her job.

2. tries to change how his or her job is executed in order to be more effective.

3. tries to bring about improved procedures for the work unit or department.

4. tries to institute new work methods that are more effective for the company.

5. tries to change organizational rules or policies that are nonproductive or counterproductive.

6. makes constructive suggestions for improving how things operate within the organization.

7. tries to correct a faulty procedure or practice.

8. tries to eliminate redundant or unnecessary procedures.

9. tries to implement solutions to pressing organizational problems.

10. tries to introduce new structures, technologies, or approaches to improve efficiency.

Performance Questionnaire (7-point Likert Scale)

1. He/she has usually exceeded the required performance.

2. Compared to colleagues with similar job profile and tenure, he/she excels in task achievement.

\footnotetext{
${ }^{33}$ This questionnaire is adopted from Biais et al. (2005).

${ }^{34}$ This questionnaire is taken from Morrison and Phelps (1999).
} 
3. Concerning his field of activity, he/she possesses extraordinary skills.

4. He/she possesses an extraordinary work and achievement motivation.

Action Orientation Questionnaire (7-point Likert Scale) ${ }^{35}$

1. The employee's time management does not enable him/her to complete his/her tasks on time.

2. The employee does not hesitate to implement decisions.

3. The thorough analysis of a task paralyses his/her actions.

4. Even if he/she is working on an urgent task, he/she tends to interrupt it to do something else in between.

5. If multitasking is necessary, he/she has difficulties organizing everything effectively.

6. If he/she has to complete an unpleasing task, he/she likes to procrastinate.

7. Whatever he/she puts on a day's schedule is finished in the evening.

8. If he/she has to complete too many tasks at once, he/she has problems deciding which one to start with.

9. It is easy for him/her, to adhere to his/her priorities at work.

Creativity Questionnaire (7-point Likert Scale)

1. The employee has the ability to quickly find usable solutions for novel problems.

2. The employee has extraordinary ideas that help advancing the project.

3. The employee has the ability to create something completely new out of existing things.

4. The employee looks for solutions outside of ordinary patterns.

Gestalt Motivation Questionnaire (7-point Likert Scale) ${ }^{36}$

1. If I delegate a task to him/her, he/she does anything to fully implement it.

2. If he/she has set a goal, he/she consequently strives for it.

3. If he/she undertakes something, he/she will only be satisfied if he/she accomplishes it.

4. If things go wrong, he/she increases his/her effort even more.

5. He/she is inclined to work hard and persistently.

6. He/she approaches problems in an active way.

7. If something goes wrong, he/she immediately looks for solutions.

8. If possibilities arise to shape something, he/she exploits them.

9. He/she immediately takes the initiative, if no one else does it.

10. He/she quickly avails him/herself of opportunities to achieve his/her goals.

11. He/she usually does more than required from him/her.

12. He/she is particularly good in implementing ideas.

\footnotetext{
${ }^{35}$ This questionnaire is adopted from Hossiep and Paschen (2003)

${ }^{36}$ This questionnaire is adopted from Hossiep and Paschen (2003).
} 


\section{Appendix E: Translation of Instructions}

\section{Instructions for the Ice Cream Task}

You are now taking part in a scientific study. A research foundation has provided funds for this research. Please read the following instructions carefully. Everything that you need to know in order to participate in this experiment is explained below. Should you have any difficulties in understanding these instructions please notify us. We will answer your questions at your cubicle.

During the course of the experiment you can earn Taler. The amount that you earn during the experiment depends on your decisions. All the gains that you make during the course of the experiment will be exchanged into cash at the end of the experiment.

The exchange rate will be: 75 Taler $=1 \mathrm{CHF}$

At the end of the experiment, you will receive your earned amount in cash.

Please note that communication between participants is strictly prohibited during the experiment. In addition we would like to point out that you may only use the computer functions which are required for the experiment. In case you have any questions, dont hesitate to ask us. An instructor will answer your questions at your cubicle.

\section{Detailed procedures for the first part of the experiment}

In this part of the experiment, you will take on the role of an individual running an ice cream stand. There will be 20 periods in which you will have to make decisions on how to run the business in order to maximize profit. These decisions will involve the location of the stand, the flavour of the ice cream, the sugar content and flavour intensity, and the ice cream color and price. You can freely choose all these variables. Your goal is to chose them such that you achieve maximal profit. At the end of each period, you will learn what profits you made during that period. You will also hear some customer reactions that may help you with your choices in the following periods. The decisions you make in one period, will be the default choices for the next period. 


\section{Previous Manager Guidelines}

Dear X,

I have enclosed the following guidelines that you may find helpful in running your ice cream stand. These guidelines are based on my previous experience running this stand. When running my business, I followed these basic guidelines:

- Location: Business District

- Sugar Content: 3\%

- Flavour Intensity: 7\%

- Ice Color: light

- Price: 8.2 Taler

- Flavour: Orange

With these choices, I was able to make an average profit of about 90 Taler per period. I have experimented with alternative choices of sugar and flavour intensity, as well as ice cream color and price. The above choices were the ones I found to be the best. I have not experimented with alternative choices of location though. They may require very different strategies. There is another ice cream stand in town which is famous for his chocolate-, vanilla-, straciatella- and strawberry icecream. It makes no sense to sell these flavours. Otherwise it is known that the demand for ice cream flavours is typical for the German speaking area. I also know that the flavour has no impact on the optimal price, color, flavour intensity or sugar content.

Regards,

Previous Manager

\section{Payment}

Your compensation will be based on the profits you make with your lemonade stand. You will get paid your own ice cream stand profits in the last 10 periods of the experiment. The profit achieved in periods 1-10 is not relevant for your own payment.

Example:

If your income in periods 11-20 was 3000 Taler, you will receive $40 \mathrm{CHF}$ at the end of the study in cash. 


\section{Instructions for the Elicitation of Ambiguity Aversion}

We measured subjects' ambiguity aversion in an experiment that took place after the ice cream task. Subjects were given the following instructions:

You now have the possibility to participate in a series of lotteries. Potential earnings will be added to your overall income, potential losses will be subtracted from your overall income. At the end, one lottery will be randomly chosen. Your income will depend on your decisions in the chosen lottery and the outcome of the lottery.

In the following, there are two urns and each urn contains 20 balls, which are either red or blue. You have to decide from which urn you want to draw a ball.

If the ball is red, you receive $8 \mathrm{CHF}$. If the ball is blue, you receive $0 \mathrm{CHF}$.

- Urn 1 contains 20 balls which can randomly be either red or blue.

- Urn 2 contains rd and blue balls in known quantities.

Please choose for each of the following lotteries whether you want to draw a ball from urn 1 or urn 2:

1. Lottery: Draw from urn 2 which contains 16 red and 4 blue balls, or draw from urn 1 which contains 20 balls that are either red or blue.

2. Lottery: Draw from urn 2 which contains 14 red and 6 blue balls, or draw from urn 1 which contains 20 balls that are either red or blue.

3. Lottery: Draw from urn 2 which contains 12 red and 8 blue balls, or draw from urn 1 which contains 20 balls that are either red or blue.

4. Lottery: Draw from urn 2 which contains 10 red and 10 blue balls, or draw from urn 1 which contains 20 balls that are either red or blue.

5. Lottery: Draw from urn 2 which contains 8 red and 12 blue balls, or draw from urn 1 which contains 20 balls that are either red or blue.

6. Lottery: Draw from urn 2 which contains 6 red and 14 blue balls, or draw from urn 1 which contains 20 balls that are either red or blue.

7. Lottery: Draw from urn 2 which contains 4 red and 16 blue balls, or draw from urn 1 which contains 20 balls that are either red or blue. 